National Marine

Fisheries Service

Fishery Bulletin

Spencer F. Baird

NOAA

as established in 1881 ๙

Abstract-Between 1997 and 2011, the National Marine Fisheries Service conducted 50 depletion experiments to examine efficiency of survey gear for capturing clam species and to estimate stock density for populations of Atlantic surfclams (Spisula solidissima) and ocean quahogs (Arctica islandica) by using commercial hydraulic dredges. The Patch model was formulated to estimate gear efficiency and organism density from the depletion experiment data. The range of efficiencies estimated is substantial, leading to uncertainty in the application of these estimates in stock assessment. Known values of 4 measures of experimental performance for each of the 50 depletion experiments conducted in the field were compared with values of those same characteristics from 9000 simulated depletion experiments, values that were assumed to represent a suite of conditions that might also occur in the corresponding field experiment. These comparisons allow analyses of the quality of field experiments that would otherwise not be possible and provide evidence for weighting the results of field experiments beyond traditional measures of uncertainty. The characteristics of performance were used to identify a subset of field experiments that were more likely to have produced inaccurate estimates of gear efficiency, potentially introducing bias and, as a result, lowering the efficiency estimates in the entire depletion data set.

Manuscript submitted 31 March 2021. Manuscript accepted 4 November 2021. Fish. Bull. 119:274-293 (2021).

Online publication date: 24 November 2021. doi: $10.7755 /$ FB.119.4.7

The views and opinions expressed or implied in this article are those of the author (or authors) and do not necessarily reflect the position of the National Marine Fisheries Service, NOAA.

\title{
Discriminating between high- and low-quality field depletion experiments through simulation analysis
}

\author{
Leanne M. Poussard (contact author) ${ }^{1}$ \\ Eric N. Powell ${ }^{1}$ \\ Daniel R. Hennen² \\ Email address for contact author: leanne1 poussard@gmail.com \\ ${ }^{1}$ Gulf Coast Research Laboratory \\ University of Southern Mississippi \\ 703 East Beach Drive \\ Ocean Springs, Mississippi 39564 \\ ${ }^{2}$ Northeast Fisheries Science Center \\ National Marine Fisheries Service, NOAA \\ 166 Water Street \\ Woods Hole, Massachusetts 02543
}

The implementation of a definitive measure of dredge efficiency for analyzing shellfish survey data substantially improves the estimation of abundance. Commonly, depletion experiments are used to estimate gear efficiency and population density for sessile and sedentary species in a target area (Leslie and Davis, 1939; Skalski et al., 1983; Lasta and Iribarne, 1997; Gedamke et al., 2005; Wilberg et al., 2013). These experiments are conducted by dredging over the same area and tracking the decline in catch of a target organism per dredge tow. Other dredge efficiency quantification methods, such as use of an underwater camera in between dredge tows, have also been used (Chai et al., 1992; Ragnarsson and Thórarinsdóttir, 2002; Morson et al., 2018). For a range of dry dredges, estimates exist for their efficiency for catching epibenthic animals, including oyster (Powell et al., 2007; Morson et al., 2018), clam (Pezzuto et al., 2010), crab (Vølstad et al., 2000; Wilberg et al., 2013), and scallop (Lasta and Iribarne, 1997; Beukers-Stewart and
Beukers-Stewart ${ }^{1}$ ) species. By comparison, highly efficient hydraulic dredges are the primary gear type used to capture infaunal clam species (Da Ros et al., 2003; Hauton et al., 2007; Moschino et al., 2003; Gilkinson et al., 2005; Meseck et al., 2014). Hydraulic dredges increase the catchability of the target organism by using water pressure to liquefy the sediment (Da Ros et al., 2003; Gilkinson et al., 2003; Hauton et al., 2007; Meseck et al., 2014).

The ocean quahog (Arctica islandica) and the Atlantic surfclam (Spisula solidissima) support substantial fisheries that operate on the continental shelf of the northeastern United States and are captured exclusively by using hydraulic dredges because of the depths at which they are found. A typical hydraulic dredge is a large rectangular

\footnotetext{
${ }^{1}$ Beukers-Stewart, B. D., and J. S. BeukersStewart. 2009. Principles for the management of inshore scallop fisheries around the United Kingdom. Report to Natural England, Scottish Natural Heritage and Countryside Council for Wales. Univ. York, Mar. Ecosyst. Manage. Rep. 1, 58 p. [Available from website.]
} 
box, 2.4-4.0 $\mathrm{m}$ wide and constructed of evenly spaced steel bars, and is towed over a seabed (Meyer et al., 1981; Lambert and Goudreau, 1996). A manifold at the head of a dredge distributes high-pressure water from a shipboard pump through a connecting hose. The water is focused with a series of jets onto the seabed, liquefying the sediment and unearthing the clams for capture by the dredge. Hydraulic dredges, widely used in clam fisheries (Parker, 1971; Hauton et al., 2007; Sala et al., 2017), are necessary for the commercial capture of the ocean quahog and Atlantic surfclam because of the depth and distance from shore at which these species are found and the fact that the fishery depends on the high volume and low unit cost of its catch. Therefore, rapid and efficient capture methods are economically essential.

A series of depletion experiments were conducted by the National Marine Fisheries Service (NMFS) between 1997 and 2011 on commercial clam vessels targeting populations of Atlantic surfclams and ocean quahogs off the northeastern and mid-Atlantic coasts of the United States to estimate the efficiency of both commercial hydraulic dredges. The exact locations of these depletion experiments are specified in appendix 3 of NEFSC (2017a, 2017b) (Fig. 1). As is often the case, estimates of dredge efficiency varied widely between individual experiments (Vølstad et al., 2000; Powell et al., 2007; Hennen et al., 2012; Wilberg et al., 2013; Morson et al., 2018). Very little is known about how environmental and sampling conditions influence the efficiency of a hydraulic dredge, factors that are likely the source of variation between experiments. Consequently, estimates of gear efficiency based on depletion experiments are a key source of uncertainty in the stock assessments for the Atlantic surfclam and ocean quahog.

The Patch model was developed to analyze the results of depletion experiments to estimate the efficiency of capture of sedentary species, such as the Atlantic surfclam and ocean quahog (Rago et al., 2006). The Patch model has been rigorously tested in previous studies (Hennen et al., 2012) and has been used to inform stock assessments of species, such as the Atlantic surfclam, ocean quahog, monkfish (Lophius americanus) (NEFSC, 2010a), and Atlantic sea scallop (Placopecten magellanicus) (NEFSC, 2010b; NMFS, 2011), that are commercially fished along the mid-Atlantic coast of the United States. Over 14 years, 50 depletion experiments were carried out along the continental shelf off the coasts of Massachusetts, Long Island in New York, and New Jersey and off the Delmarva
Peninsula in Delaware, Maryland, and Virginia to determine the efficiency of hydraulic dredges used in the fisheries that target Atlantic surfclams and ocean quahogs. The Patch model provides estimates of capture efficiency and average density of organisms in the target area by tracking the relative reduction in catch for each dredge tow. Theoretically, capture efficiency is a measurable characteristic of the gear as well as of the species (Hennen et al., 2012).

In a field depletion experiment, the dredge is towed over the same ground repeatedly while covering the majority of a predetermined area. Depletion experiments are conducted in a rectangular area on average about 10 dredge widths wide (23-24 m) and about 400-1000 m long. A series of intersecting dredge tows are conducted across the selected area, with the path of the dredge tow beginning at one short end of the rectangle and finishing at the opposite end (Fig. 2). The tow paths are not parallel, rather the paths overlap and intersect at various points in the area by design in order to meet the requirements of the Patch

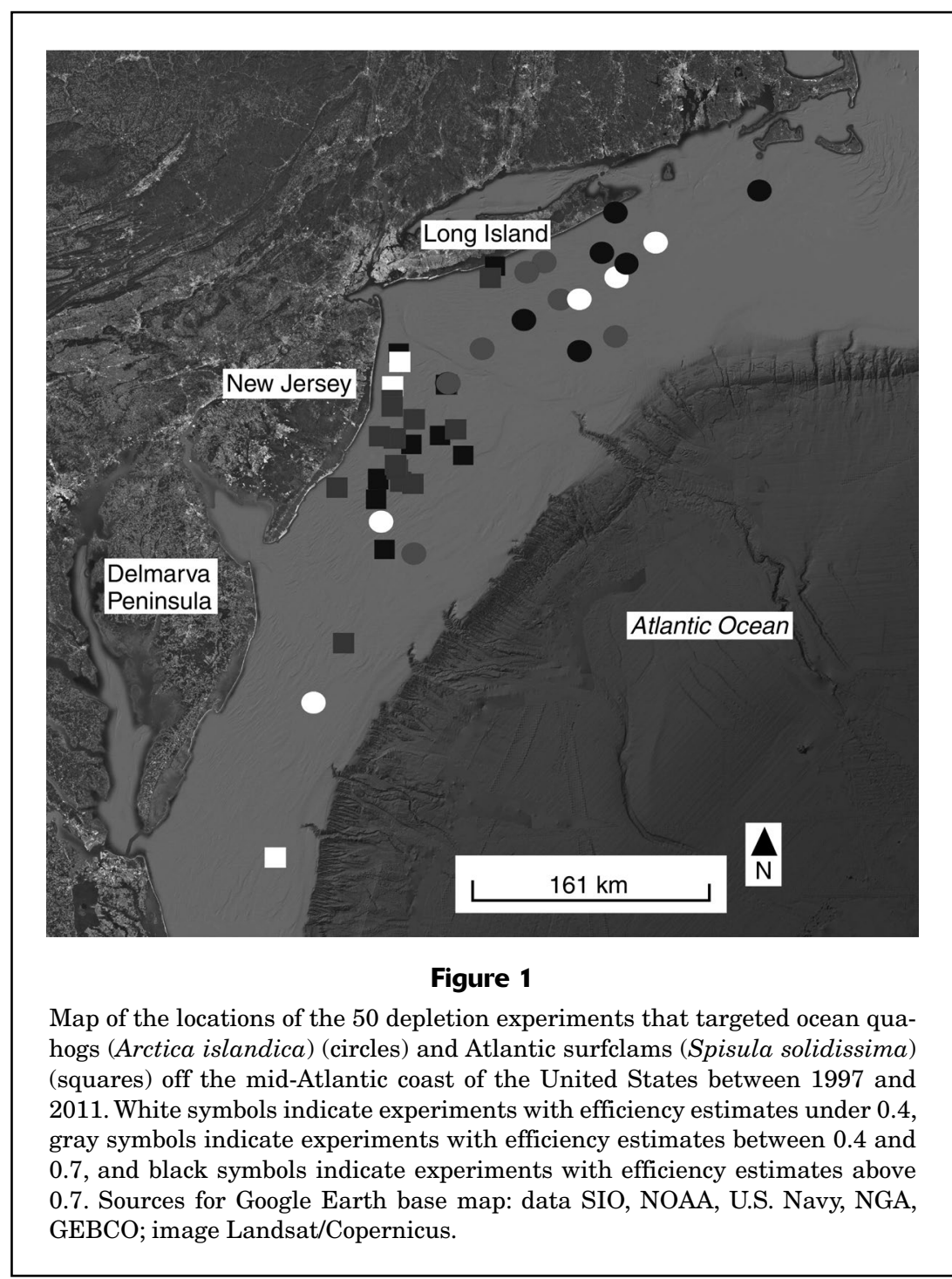




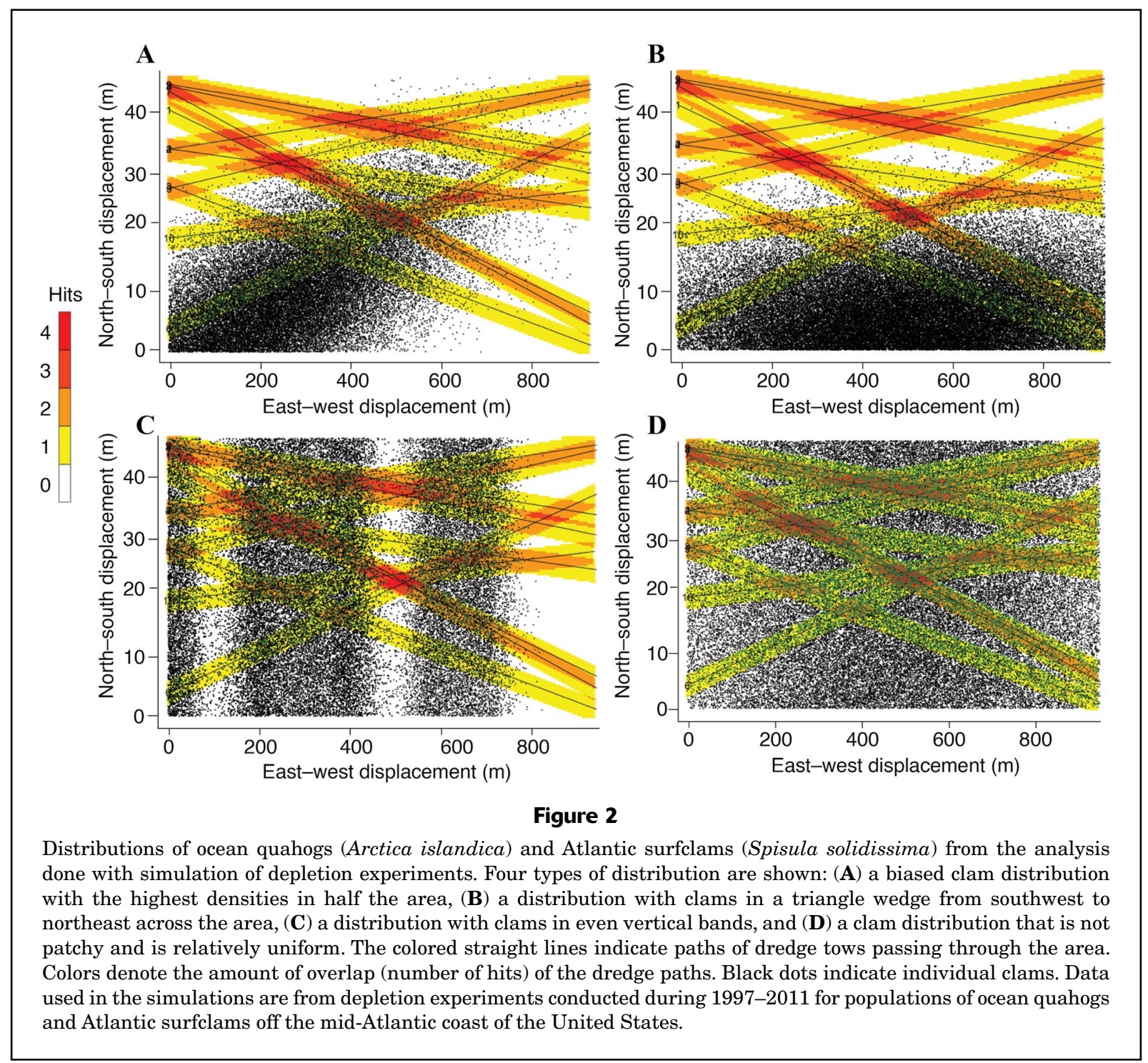

model. The experiment requires the assumptions that all catches are random samples and that no organisms are transported into or out of the study site during the experiment (Leslie and Davis, 1939). The catch and the incremental dredge positions are recorded for each dredge tow. Over the course of the depletion experiment, catch per tow decreases; this rate of decline is proportional to the efficiency of the dredge (Hennen et al., 2012). If the rate of decline is steep, the dredge is highly efficient, and if it is shallow, the dredge may not be efficient.

Field depletion experiments can take hours to complete and require much effort on the part of scientists and crew on the ship. Therefore, it is important to know if experiments produce reliable efficiency estimates for the gear used and to evaluate poor performance that might be avoided in future endeavors. Poussard et al. (2021) used simulation analysis to determine best practices for depletion experiments and evaluated which range of experiment protocols were most likely to provide high-quality estimates of capture efficiency. Here, we report results of the use of the simulation data to identify the quality of field depletion experiments. The depletion experiment data set analyzed, obtained from NMFS $\left(\mathrm{Hennen}^{2}\right.$ ), is unique at the time of this writing. No other data set from depletion experiments is this expansive.

Analyzing data from the NMFS hydraulic dredge depletion experiments provides an improved understanding of the sources of uncertainty in efficiency estimates, including the characteristics of experimental protocol and environmental factors affecting gear efficiency. In our study, first the characteristics of these experiments (e.g., dredge size, depth, and geographic region) were summarized, and then results of simulated depletion experiments were compared with those of the field depletion

\footnotetext{
${ }^{2}$ Hennen, D. 2019. Personal commun. Northeast Fish. Sci. Cent., Natl. Mar. Fish. Serv., NOAA, 166 Water St., Woods Hole, MA 02543.
} 
experiments conducted on Atlantic surfclam and ocean quahog stocks by using a series of experimental quality measurements. The simulated depletion experiments have the advantage of being fully controlled, and the accuracy and precision of the measurement estimates they provide can be evaluated. In this analysis, a set of simulated experiments was matched to each field experiment. This set of simulated experiments was assumed to represent a suite of conditions that might also occur in the corresponding field experiment. The results of these comparisons allow examination of the quality of field experiments and provide evidence for weighting the results of field experiments beyond traditional measures of uncertainty.

\section{Materials and methods}

\section{The Patch model}

For estimation of the catchability coefficient $(q)$, depletion experiments allow correction of survey catch by using the equations $N=S A / q$ and $q=\frac{\alpha e}{A}$, where $N$ is stock abundance or biomass and $S A$ is the swept area average of all tows in the experiment area. The $q$ is obtained from $\alpha$, the area swept by the sampling gear; $e$, the dredge efficiency; and $A$, the spatial domain of the estimates (Paloheimo and Dickie, 1964). The $\alpha$ is calculated as the distance the dredge is towed multiplied by the width of the dredge. See Figure 2 for a visual representation of the dredge tows in an experiment area.

The expected catch of organisms in any tow $i, E\left(C_{\mathrm{i}}\right)$, given initial density of the target organisms $\left(D_{0}\right)$ and the cumulative catch from previous tows, $T_{\mathrm{i}-1}$, can be calculated as follows:

$$
E\left(C_{\mathrm{i}}\right)=q\left(D_{0}-T_{\mathrm{i}-1}\right)
$$

assuming each tow covers the same spatial domain. In reality, this relationship is more complex because each tow covers only a portion of the area of the experiment. Incorporating the portion of the area that has already been hit by the dredge prior to tow $i$, also known as the hit matrix (Hennen et al., 2012), gives the expected catch per tow $i$ as follows:

$$
E\left(C_{\mathrm{i}}\right)=\left(E A S_{\mathrm{i}}\right) D_{0},
$$

where EAS is the effective area swept, defined as the total area swept by the dredge in tow $i$, taking into account the portion of the experimental area hit by the dredge in previous tows. The EAS is calculated as follows:

$$
E A S=e a_{\mathrm{i}} \sum_{\mathrm{j}=1}^{\mathrm{i}} f_{\mathrm{i}, \mathrm{j}}(1-e \gamma)^{\mathrm{j}-1}
$$

where $e=$ the capture efficiency as estimated by the Patch model;

$a_{\mathrm{i}}=$ the area swept by tow $i$;

$f_{\mathrm{i}, \mathrm{j}}=$ the fraction of the area $a_{\mathrm{i}}$ hit by the dredge $j$ times in previous tows; and

$\gamma=$ the ratio of cell size to dredge width.
Rago et al. (2006) divided the experimental area into cells twice the width of the dredge. Hennen et al. (2012) removed $\gamma$ by reducing the cells to points, eliminating the need to calculate cell size and, as a result, improving accuracy and precision of efficiency estimates. In this study, the latter method was used.

The negative binomial distribution was used to describe the dispersion of animals in the area of the experiment in order to account for extra variation in observed catches and for catch from previous tows when estimating catch in tow $i$. In this method, the cumulative spatial pattern of removal of animals is used to define capture probability for each organism. The negative binomial distribution of catch can be expressed as a function of $D_{0}, k$ (the dispersion parameter), and EAS (Rago et al., 2006):

$$
\begin{aligned}
P\left(C_{\mathrm{i}} \mid D_{0}, k, E A S\right) & =\left(\frac{k}{D_{0}(E A S)+K}\right)^{\mathrm{k}}\left(\frac{D_{0}(E A S)}{D_{0}(E A S)+\mathrm{k}}\right)^{\mathrm{C}_{\mathrm{i}}} \\
& \times \prod_{\mathrm{j}=1}^{\mathrm{C}_{\mathrm{i}}} \frac{k+j-1}{j} .
\end{aligned}
$$

The log likelihood $(L L)$ function allows estimation of the dispersion parameter, initial density, and capture efficiency, given the hit matrix, catch, and area swept:

$$
\begin{aligned}
L L\left(D_{0}, k, e, \gamma \mid C_{\mathrm{i}}, E A S\right)= & k \sum_{\mathrm{i}=1}^{\mathrm{n}} \log (k) \\
& -\log \left(D_{0}(E A S)+k\right) \\
& +\sum_{\mathrm{i}=1}^{\mathrm{n}}\left(\log \left(D_{0}(E A S)\right)\right. \\
& -\log \left(D_{0}(E A S)+k\right) \\
& +\sum_{\mathrm{i}=1}^{\mathrm{n}} \sum_{\mathrm{j}=1}^{\mathrm{C}_{\mathrm{i}}} \log (k+j-1) \\
& -\sum_{\mathrm{i}=1}^{\mathrm{n}} C_{\mathrm{i}} !
\end{aligned}
$$

where $n=$ the total number of tows in the sequence; and $!=$ a factorial.

\section{Simulated data sets}

Poussard et al. (2021) reported the results of 5400 depletion experiments simulated in a block design in which animal density, "true" dredge efficiency, the number of tows per experiment, and the dispersion of animals on the bottom were varied. For the purposes of the study we describe here, 3600 additional simulations with 15 and 25 dredge tows were conducted in order to provide a simulated data set that is comparable to the data from experiments conducted in the field, for a total of 9000 simulations (Table 1). The simulated data set included 5 options for the number of dredge tows for each experiment, 4 dispersions of individual clams in the area, 3 clam densities, and 3 values for the true efficiency of the dredge. Fifty simulations were conducted for each combination of factors (e.g., 50 simulations were conducted with 25 tows that had a dredge efficiency of 0.9 and clams distributed evenly through the area with a density of 3.00 individuals $/ \mathrm{m}^{2}$, and 50 more simulations were 


\section{Table 1}

Characteristics from the analysis done with simulation of depletion experiments in a block design. All combinations of the 4 parameters were simulated: 50 simulations for each tetradic combination were conducted. The type of clam distribution is denoted as follows: uniform across the area (NP), patches oriented across the narrow dimension $(\mathrm{P})$, patches oriented longitudinally (HP), and patches of a triangular nature emanating from one side of the rectangle (T). True efficiency is efficiency of the dredge for capture of shellfish. The data set used in the simulations came from depletion experiments conducted for populations of ocean quahogs (Arctica islandica) and Atlantic surfclams (Spisula solidissima) off the mid-Atlantic coast of the United States between 1997 and 2011.

\begin{tabular}{llllll}
\hline Characteristic & \multicolumn{5}{c}{ Values } \\
\hline True efficiency & 0.9 & 0.6 & 0.2 & & \\
Clam density & 0.75 & 1.50 & 3.00 & & \\
$\quad\left(\right.$ individuals $/ \mathrm{m}^{2}$ ) & & & & & \\
Clam distribution & $\mathrm{NP}$ & $\mathrm{HP}$ & $\mathrm{P}$ & $\mathrm{T}$ & \\
No. of tows & 40 & 25 & 20 & 15 & 10 \\
& & & & &
\end{tabular}

conducted with all the same factors except with a density of 1.50 individuals $/ \mathrm{m}^{2}$, and so on). Fifty tow patterns were randomly generated for each tow number.

Here we discuss 4 useful measures for comparing depletion experiments, along with the estimates of efficiency and density. The 4 characteristics are the EAS (Equation 3), the coefficient of variation (CV) for the efficiency estimate $\left(\mathrm{CV}_{\mathrm{E}}\right)$, the $\mathrm{CV}$ of the $k$ parameter $\left(\mathrm{CV}_{\mathrm{K}}\right)$ (the negative binomial dispersion parameter), and the overlap score (OS) describing tow overlap (Equation 7). The CVs were calculated by using the delta method standard deviation of estimates from the Patch model divided by the means of the estimates obtained from the log likelihood equation (Equation 5).

The OS is a measure that describes tow overlap that does not depend on estimated efficiency or the spatial dimensions of the site. The OS is derived directly from the hit matrix (Hennen et al., 2012), where the $n$ rows equal the number of tows in the experiment and the $m$ columns are the number of points touched $m$ times previously. The highest possible amount of overlap for any depletion site would be the exact duplication of the longest tow in each sequence (the row with the most total points touched), repeated $n$ times $\left(O S_{\max }\right)$. For tow $i$, the OS is calculated with this equation:

$$
O S_{\mathrm{i}}=\sum_{\mathrm{h}=\mathrm{i}}^{\mathrm{m}}\left(p_{\mathrm{i}, \mathrm{h}} h\right)
$$

where $p_{\mathrm{i}, \mathrm{h}}=$ the number of points in hit matrix row $i$ and column $h$.

The OS for each tow sequence is then calculated with this equation:

$$
O S=\frac{\sum_{\mathrm{i}}^{\mathrm{n}} O S_{\mathrm{i}}}{O S_{\max }} \times 100 .
$$

The value of OS varied nonlinearly with tow number. As a consequence, the values were detrended by using the mean OS value for that tow number to standardize all OS values of the same tow number. A higher value of OS equates to more dredge overlap in the tow structure of an experiment for a given number of tows.

For the simulations, where the true efficiency (TrueEff) was already known (efficiency values were $0.2,0.6$, and 0.9), Poussard et al. (2021) calculated the percent error in efficiency from the Patch model estimate of efficiency, $E s t E f f$, and the inherent efficiency specified in the simulation, TrueEff, as follows:

$$
\text { Error }=\frac{\text { EstEff }- \text { TrueEff }}{\text { TrueEff }} \times 100 .
$$

On the basis of the results of their analysis of simulated depletion experiments, Poussard et al. (2021) concluded that a depletion experiment is more likely to produce accurate gear efficiency estimates if it employs a high number of dredge tows (e.g., 40 tows per experiment compared with 10 or 15 tows), maximizes the amount of intersection in tow paths, occurs over a homogenous as opposed to patchy distribution of clams, and uses a highly efficient dredge. The results of these simulations were compared with those of the field depletion experiments by using the set of 4 characteristics to match the field experiments to simulated experiments with similar characteristics. The known errors in the set of comparable simulated experiments were then used as a proxy for the reliability of each of the 50 field experiments.

\section{Application of simulations: error estimates}

Field experiments varied in the length of the depletion site and the width of the dredge used. For statistical analysis, EAS was standardized to a dredge width of $3.81 \mathrm{~m}$ and a site length of $960 \mathrm{~m}$, consistent with the simulation data set of Poussard et al. (2021), by using a proportional standardization. All EAS values used were the average values per tow, rather than the total values, to take into account the large range in tow numbers among experiments.

A principal components analysis was conducted on the simulation data set to determine if the 4 measures that describe depletion performance (EAS, $\mathrm{CV}_{\mathrm{E}}, \mathrm{CV}_{\mathrm{K}}$, and $\mathrm{OS}$ ) were correlated and, if so, to derive new orthogonal metrics. The data were standardized to a mean of 0 and a standard deviation of 1 , and factors were designated by using Varimax rotation. Factor loadings indicate each of the 4 characteristics loaded on separate axes with loads exceeding 0.95; therefore, the 4 measures in their original form are approximately orthogonal and provide independent information for evaluating experimental performance.

Field experiments were matched to a subset of the simulated depletion experiments through an iterative process. For each field experiment, the values of the 4 characteristics were compared with values from the 9000 simulations. Data from field experiments were compared with the simulation data set by determining whether the 
values of each of the 4 characteristics for a given field depletion experiment fell above or below the mean value for the characteristic from the simulation data set. This comparison generated a 4-digit integer sequence (e.g., 1011) for any given field experiment with the numeral 1 assigned if the field experiment measure fell above the mean of the simulated experiment measures and a with the numeral 0 assigned if the measure fell below the mean.

The same set of integer sequences were calculated for each simulation and compared with the mean of the characteristics for all simulated experiments. Then the subset of simulations that have the same sequence as the field experiment was extracted from the data set. The means of the measures for this subset were again calculated and compared with those of the field experiment, generating a new 4-digit sequence. This sequence, in turn, was used to extract a subset of simulated experiments of identical sequence. This process was repeated sequentially on each extracted subset, with the mean values for the simulated experiments being updated by using only the extracted subset, until none of the final subset of simulations had the same 4-digit value as the chosen field experiment. This group of simulations was considered the most comparable to the field experiment in question out of all the simulations. This "most comparable" subset typically numbered 2-20 of the 9000 simulations and was used to describe the average values for the simulated 4 characteristics and the average error in efficiency most appropriate for comparison with the known values (Tables 2 and 3 ).

Each simulation in the extracted subset of simulations was run by using a specified dispersion of clams. The distributions of clams were organized as follows: a relatively

\section{Table 2}

Parameters from 19 simulations that were most comparable with data from the depletion experiment OQ08-02. Type of clam distribution is denoted as uniform (NP), vertical bands (P), clams in half the area (HP), and diagonal across the area (T). Characteristics used to describe the experiments are the effective area swept (EAS), the coefficient of variation (CV) for the efficiency estimate $\left(\mathrm{CV}_{\mathrm{E}}\right)$, and the $\mathrm{CV}$ of the $k$ parameter $\left(\mathrm{CV}_{\mathrm{K}}\right)$, which is the negative binomial dispersion parameter. The estimated efficiency of depletion experiment OQ08-02 is 0.79507. The data set used in the simulations came from depletion experiments conducted during 1997-2011 for ocean quahogs (Arctica islandica) off the mid-Atlantic coast of the United States. See Figure 1 for the locations where the experiments were conducted.

\begin{tabular}{|c|c|c|c|c|c|c|}
\hline & & & \multicolumn{4}{|c|}{ Parameter } \\
\hline \multicolumn{3}{|c|}{ Simulation and OQ08-02 values } & $\mathrm{CV}_{\mathrm{E}}$ & $\mathrm{CV}_{\mathrm{K}}$ & \multicolumn{2}{|c|}{$\operatorname{EAS}\left(\mathrm{m}^{2}\right)$} \\
\hline \multicolumn{3}{|c|}{ Average values from simulations } & 5.477 & 41.966 & \multicolumn{2}{|c|}{$21,331.1$} \\
\hline \multicolumn{3}{|c|}{ Values from experiment OQ08-02 } & 9.361 & 35.067 & \multicolumn{2}{|c|}{$24,604.8$} \\
\hline \multicolumn{3}{|c|}{ Mean absolute error in efficiency estimate: } & 0.1003 & Range: & \multicolumn{2}{|c|}{$0.0001-0.4000$} \\
\hline \multicolumn{7}{|c|}{ Parameter } \\
\hline $\begin{array}{l}\text { Error in } \\
\text { efficiency } \\
\text { estimate }\end{array}$ & $\begin{array}{c}\text { Density } \\
\text { (individuals } / \mathrm{m}^{2} \text { ) }\end{array}$ & $\begin{array}{c}\text { Clam } \\
\text { distribution }\end{array}$ & $\begin{array}{c}\text { True } \\
\text { efficiency }\end{array}$ & $\begin{array}{c}\mathrm{CV}_{\mathrm{E}} \\
\text { estimate }\end{array}$ & $\begin{array}{c}\mathrm{CV}_{\mathrm{K}} \\
\text { estimate }\end{array}$ & $\operatorname{EAS}\left(\mathrm{m}^{2}\right)$ \\
\hline 0.6667 & 0.75 & HP & 0.6 & 0.0090 & 38.4412 & $22,601.94$ \\
\hline 0.6667 & 1.50 & HP & 0.6 & 0.0090 & 38.6189 & $22,601.94$ \\
\hline 0.6667 & 3.00 & HP & 0.6 & 0.0190 & 37.5421 & $22,771.00$ \\
\hline 0.1517 & 0.75 & $\mathrm{P}$ & 0.6 & 13.4774 & 47.8368 & $22,551.50$ \\
\hline 0.0633 & 0.75 & $\mathrm{P}$ & 0.6 & 14.3416 & 46.6667 & $22,696.44$ \\
\hline 0.1500 & 0.75 & $\mathrm{P}$ & 0.6 & 7.3768 & 47.6762 & $23,019.59$ \\
\hline 0.1050 & 1.50 & $\mathrm{P}$ & 0.6 & 9.4721 & 46.1634 & $22,653.81$ \\
\hline 0.0633 & 1.50 & $\mathrm{P}$ & 0.6 & 6.3793 & 47.7372 & $22,696.44$ \\
\hline 0.0883 & 1.50 & $\mathrm{P}$ & 0.6 & 5.4058 & 47.5397 & $23,019.59$ \\
\hline 0.6667 & 0.75 & $\mathrm{~T}$ & 0.6 & 0.0710 & 41.7476 & $22,601.94$ \\
\hline 0.6667 & 0.75 & $\mathrm{~T}$ & 0.6 & 0.0200 & 41.2644 & $22,771.00$ \\
\hline 0.6667 & 1.50 & $\mathrm{~T}$ & 0.6 & 0.0190 & 41.0180 & $22,771.00$ \\
\hline 0.6667 & 3.00 & $\mathrm{~T}$ & 0.6 & 0.1210 & 41.6268 & $22,601.94$ \\
\hline 0.0905 & 0.75 & NP & 0.6 & 5.7007 & 42.9225 & $20,596.54$ \\
\hline 0.0572 & 0.75 & NP & 0.6 & 4.9920 & 41.7308 & $20,775.93$ \\
\hline 0.0359 & 0.75 & NP & 0.6 & 6.4963 & 40.6921 & $20,679.71$ \\
\hline 0.0778 & 0.75 & $\mathrm{P}$ & 0.6 & 7.6546 & 48.6502 & $20,596.54$ \\
\hline 0.0017 & 0.75 & $\mathrm{P}$ & 0.6 & 6.5863 & 48.5524 & $20,807.33$ \\
\hline 0.0483 & 3.00 & $\mathrm{P}$ & 0.6 & 7.0053 & 38.5597 & $20,807.33$ \\
\hline
\end{tabular}




\section{Table 3}

Parameters from 19 simulations that were most comparable with data from the depletion experiment SC04-01. Type of clam distribution is denoted as vertical bands (P), clams in half the area (HP), and diagonal across the area (T). Characteristics used to describe the experiments are the effective area swept (EAS), the coefficient of variation (CV) for the efficiency estimate $\left(\mathrm{CV}_{\mathrm{E}}\right)$, and the $\mathrm{CV}$ of the $k$ parameter $\left(\mathrm{CV}_{\mathrm{K}}\right)$, which is the negative binomial dispersion parameter. The estimated efficiency of depletion experiment SC04-01 is 0.53334. The data set used in the simulations came from depletion experiments conducted during 1997-2011 for Atlantic surfclams (Spisula solidissima) off the mid-Atlantic coast of the United States. See Figure 1 for the locations where the experiments were conducted.

\begin{tabular}{|c|c|c|c|c|c|c|}
\hline & & & \multicolumn{4}{|c|}{ Parameter } \\
\hline \multicolumn{3}{|c|}{ Simulation and SC04-01 values } & $\mathrm{CV}_{\mathrm{E}}$ & $\mathrm{CV}_{\mathrm{K}}$ & \multicolumn{2}{|c|}{$\operatorname{EAS}\left(\mathrm{m}^{2}\right)$} \\
\hline \multirow{2}{*}{\multicolumn{3}{|c|}{$\begin{array}{l}\text { Average values from simulations } \\
\text { Values from SC04-01 }\end{array}$}} & 14.564 & 25.703 & \multicolumn{2}{|c|}{$16,443.2$} \\
\hline & & & 19.835 & 28.085 & \multicolumn{2}{|c|}{$12,824.4$} \\
\hline \multicolumn{3}{|c|}{ Mean absolute error in efficiency estimate: } & 0.1471 & Range: & \multicolumn{2}{|c|}{$0.0000-0.5817$} \\
\hline \multicolumn{7}{|c|}{ Parameter } \\
\hline $\begin{array}{l}\text { Error in } \\
\text { efficiency } \\
\text { estimate }\end{array}$ & $\begin{array}{c}\text { Density } \\
\text { (individuals } / \mathrm{m}^{2} \text { ) }\end{array}$ & $\begin{array}{c}\text { Clam } \\
\text { distribution }\end{array}$ & $\begin{array}{c}\text { True } \\
\text { efficiency }\end{array}$ & $\begin{array}{c}\mathrm{CV}_{\mathrm{E}} \\
\text { estimate }\end{array}$ & $\begin{array}{c}\mathrm{CV}_{\mathrm{K}} \\
\text { Estimate }\end{array}$ & $\operatorname{EAS}\left(\mathrm{m}^{2}\right)$ \\
\hline 0.3083 & 1.50 & $\mathrm{HP}$ & 0.6 & 24.2038 & 26.5866 & $20,807.33$ \\
\hline 0.2533 & 1.50 & $\mathrm{HP}$ & 0.6 & 26.1968 & 26.7742 & $20,807.33$ \\
\hline 0.4250 & 3.00 & $\mathrm{HP}$ & 0.6 & 27.2515 & 26.4758 & $16,443.15$ \\
\hline 0.4633 & 3.00 & $\mathrm{HP}$ & 0.6 & 18.3371 & 26.4220 & $12,824.38$ \\
\hline 0.4133 & 3.00 & HP & 0.6 & 18.7500 & 26.8293 & $18,932.27$ \\
\hline 0.2533 & 0.75 & $\mathrm{~T}$ & 0.6 & 19.0160 & 28.5385 & $19,145.44$ \\
\hline 0.4450 & 0.75 & $\mathrm{~T}$ & 0.6 & 14.9942 & 28.6364 & $18,949.80$ \\
\hline 0.3250 & 0.75 & $\mathrm{~T}$ & 0.6 & 13.2075 & 28.5484 & $18,931.71$ \\
\hline 0.2233 & 1.50 & $\mathrm{~T}$ & 0.6 & 19.2098 & 28.5821 & $18,729.82$ \\
\hline 0.3467 & 1.50 & $\mathrm{~T}$ & 0.6 & 19.9257 & 28.7838 & $18,815.12$ \\
\hline 0.0867 & 1.50 & $\mathrm{~T}$ & 0.6 & 23.6196 & 28.9172 & $18,931.71$ \\
\hline 0.0033 & 3.00 & $\mathrm{~T}$ & 0.6 & 23.4114 & 28.8820 & $18,581.26$ \\
\hline 0.3400 & 3.00 & $\mathrm{~T}$ & 0.6 & 19.9005 & 28.8194 & $18,815.12$ \\
\hline 0.4167 & 3.00 & $\mathrm{~T}$ & 0.6 & 14.7059 & 28.0702 & $18,891.53$ \\
\hline 0.0317 & 1.50 & NP & 0.6 & 1.7609 & 25.3618 & $18,729.82$ \\
\hline 0.0250 & 1.50 & NP & 0.6 & 1.3886 & 26.9719 & $18,932.27$ \\
\hline 0.0083 & 3.00 & NP & 0.6 & 1.3091 & 24.6763 & $18,891.53$ \\
\hline 0.0383 & 0.75 & $\mathrm{P}$ & 0.6 & 2.4398 & 26.3924 & $18,757.88$ \\
\hline 0.0233 & 1.50 & $\mathrm{P}$ & 0.6 & 2.2964 & 25.0700 & $13,600.72$ \\
\hline
\end{tabular}

uniform distribution across the depletion rectangle (NP), patches oriented across the narrow dimension $(\mathrm{P})$, patches oriented longitudinally (HP), and patches of a triangular nature emanating from one side of the rectangle (T) (Fig. 2). The fraction of chosen simulations assigned to each field experiment falling into each of these categories was obtained to describe possible similarities in clam dispersion characteristics in the area occupied by the field depletion experiment.

Comparisons between field experiments and simulations were made by using 4 error terms chosen to determine which of the field depletion experiments diverged the most from the most comparable simulations identified with the 4-integer test. Two error terms, henceforth referred to as $\operatorname{Err} 1$ and Err2, describe how closely the 4 experiment measures derived from the field experiments $\left(\mathrm{EAS}, \mathrm{CV}_{\mathrm{E}}\right.$, $\mathrm{CV}_{\mathrm{K}}$, and $\mathrm{OS}$ ) agreed with the same measures obtained from the extracted subset of the simulations:

$$
\begin{gathered}
\operatorname{Err} 1=\sum_{\mathrm{j}=1}^{4} \frac{\text { abs(observed }- \text { expected })}{\text { expected }} \text { and } \\
\operatorname{Err} 2=\sum_{\mathrm{j}=1}^{4} \frac{(\text { observed }- \text { expected })^{2}}{\text { expected }}
\end{gathered}
$$

where the observed measurement value is obtained from the field experiment and the expected measurement is the average value of the extracted simulations.

The error term Err3 is the average percent error from the simulation subset obtained by comparing the field 
estimate of efficiency with the known efficiency used in the simulation (Equation 8). The error term Err3 was modified as a simple difference between the averages (observed and true efficiencies) obtained from the simulation subset as Err4:

$$
\text { Err4 }=a b s(O b s E f f-T r u e E f f) .
$$

Caveat lector. No characteristic can be used to definitively estimate the accuracy of a field depletion experiment because the true efficiency perforce is unknown. Estimates of the 4 error terms relate attributes of a large set of simulated experiments, in which combinations of 4 different depletion experiment characteristics are used to describe how precisely the Patch model estimate of efficiency returned the known efficiency specified in the simulation. In this study, comparing field experiments directly to the simulations permitted inference of the quality of field experiments. Comparisons were made by using estimates of the 4 error terms to identify field experiments that have characteristics that resemble the 4 performance characteristics in the simulations of Poussard et al. (2021).

\section{Statistics}

Unless otherwise indicated, statistical evaluation of the quality of field depletion experiments was done with SAS $9^{3}$ (SAS Institute Inc., Cary, NC). Field experiments that had estimates for 1 or more of the 4 error terms at or above the 80th percentile were compared with the remaining experiments that had 1 or more error estimate below the 80th percentile by using a Wilcoxon rank sum test (Sokal and Rohlf, 1998) to determine if the flagged subset of field experiments was a random subset of all field experiments, as determined by the error estimates and other characteristics as earlier described.

The relationship between descriptors of Patch model performance, including efficiency and density estimates, and descriptors of the experiment, such as location, depth, and target species in the field experiments, were resolved by using correspondence analysis (Clausen, 1998). For this purpose, continuous variables were classified into quartiles (1-4), and error terms were entered as 1 (below the 80th percentile) or 2 (at or above the 80th percentile). The variables used to specify the coordinate system for the correspondence analysis and a series of supplementary variables assigned coordinate positions include dredge efficiency and its CV, clam density and its CV, the $k$ parameter, EAS, OS, latitude, depth, species, region, dredge width, and the 4 error terms. Of note, the error terms were all designated as supplementary variables, meaning that they did not determine the axes in the correspondence analysis and were added retrospectively to provide context.

Pearson's correlation coefficients were calculated by using statistical software $\mathrm{R}$ (vers. 3.6.0; $\mathrm{R}$ Core Team,

\footnotetext{
${ }^{3}$ Mention of trade names or commercial companies is for identification purposes only and does not imply endorsement by the National Marine Fisheries Service, NOAA.
}

2019) for variables describing the field experiments to determine how factors, such as dredge width, experiment area width, number of tows, year, and latitude correlated with Patch model estimates of efficiency, density, and the $k$ parameter.

\section{Results}

\section{Characteristics of field depletion experiments}

The mean and median estimates of efficiency, density, and the $k$ parameter for the 50 field depletion experiments are provided in Table 4 . The mean estimate of efficiency for the 31 depletion experiments that targeted Atlantic surfclams is 0.635 , and the mean efficiency estimate for the 19 depletion experiments that targeted ocean quahogs is 0.586 (Fig. 3). The mean density estimate for depletion experiments with Atlantic surfclams is 1.50 individuals $/ \mathrm{m}^{2}$, and the mean density estimate for depletion experiments with ocean quahogs is 1.18 individuals $/ \mathrm{m}^{2}$. These densities are well above the average stock density for both species because the depletion experiments were purposely sited in high-density areas. The mean estimate of $k$ for the experiments with Atlantic surfclams is 12.10 , and the mean for the experiments with ocean quahogs is 7.72 .

Most depletion experiments that targeted ocean quahogs were conducted at higher latitudes and at deeper depths than depletion experiments that targeted Atlantic surfclams (Table 5). For depletion experiments with ocean quahogs, higher efficiency estimates were produced at the most northern locations (Fig. 1). Depletion experiments with Atlantic surfclams produced efficiency estimates that were higher off the coast of New Jersey than off the coasts of Long Island and the Delmarva Peninsula (Fig. 1).

Over the 14 years that depletion experiments were conducted, method and gear changed. Dredge width, for example, gradually increased from 2.55 to $3.81 \mathrm{~m}$. The number of dredge tows used in each experiment varied through the years as well. The majority of experiments, especially in later years, used between 15 and 20 tows, but some experiments between 1997 and 2000 used as few as 4 tows and as many as 39 tows.

\section{Correlation analysis}

Efficiency estimates for depletion experiments that targeted ocean quahogs are significantly positively correlated with latitude (Fig. 1) and the width of the dredge (Fig. 4). Efficiency is incorporated into the equation to calculate EAS; therefore, the correlation between efficiency and EAS was expected, and correlations between efficiency and other variables were reflected by correlations between EAS and those same variables. Year was incorporated into the correlation analysis to examine how characteristics changed over time. As noted, dredge width increased with year, and tow number and depth decreased over time. The $\mathrm{CV}_{\mathrm{E}}$ is 


\section{Table 4}

Mean, median, standard deviation, and coefficient of variance (CV) for estimates from the Patch model for the following parameters: dredge efficiency; clam density; the $k$ parameter, which is the negative binomial dispersion parameter; effective area swept (EAS); and the number of tows of the dredge. Estimates are based on the 50 depletion experiments conducted in the field between 1997 and 2011 for populations of ocean quahogs (Arctica islandica) and Atlantic surfclams (Spisula solidissima) off the mid-Atlantic coast of the United States. The standard deviation and CV values for efficiency and density are the averages of the delta method uncertainties associated with parameter estimation. $n=$ number of experiments.

\begin{tabular}{lcrrrr}
\hline & \multicolumn{5}{c}{ Parameter } \\
\cline { 2 - 5 } Statistic & Efficiency & $\begin{array}{c}\text { Density } \\
\left.\text { (individuals } / \mathrm{m}^{2}\right)\end{array}$ & $\begin{array}{c}k \\
\text { parameter }\end{array}$ & EAS $\left(\mathrm{m}^{2}\right)$ & $\begin{array}{c}\text { No. of } \\
\text { tows }\end{array}$ \\
\hline Ocean quahog $(n=19)$ & & & & \\
$\quad$ Mean & 0.586 & 1.184 & 7.724 & $13,688.81$ & 17.433 \\
Median & 0.629 & 0.094 & 6.165 & $13,746.99$ & 17.270 \\
Standard deviation & 0.113 & 0.646 & 3.045 & $13,471.86$ & 3.713 \\
$\quad$ Coefficient of variance & 0.357 & 16.907 & 0.613 & $13,471.86$ & 0.189 \\
Atlantic surfclam $(n=31)$ & & & & & \\
$\quad$ Mean & 0.635 & 1.496 & 12.097 & $13,570.90$ & 22.330 \\
Median & 0.590 & 0.738 & 5.689 & 7325.56 & 19.143 \\
Standard deviation & 0.131 & 1.786 & 3.011 & $14,653.21$ & 5.829 \\
Coefficient of variance & 0.206 & 12.855 & 0.351 & 0.104143 & 0.193 \\
& & & & & \\
\hline
\end{tabular}

negatively correlated with the number of tows and strongly positively correlated with the $\mathrm{CV}$ of the density estimate $\left(\mathrm{CV}_{\mathrm{D}}\right)$ (Figs. 4 and 5). In depletion experiments with Atlantic surfclams, as opposed to experiments with ocean quahogs, the $\mathrm{CV}_{\mathrm{K}}$ is significantly positively correlated with the $\mathrm{CV}_{\mathrm{D}}$ (Fig. 5). In the case of the Atlantic surfclam, no correlation exists between latitude and the efficiency estimates, but density estimates are negatively correlated with the latitude and efficiency estimates.

\section{Error estimates and Wilcoxon rank sum tests}

Field depletion experiments with parameter estimates that fall at or above the 80th percentile of their respective most comparable simulated experiments, for 1 or more of the 4 error estimates, are denoted by asterisks in Table 5 . We used the 80th percentile, corresponding to a 90 th percentile one-sided threshold, to retain a high probability of including marginal experiments in the group flagged as suspect, recognizing that this threshold may entrap some experiments of higher quality. Effectively, the goal was to err on the side of removing a few "good" field depletion experiments rather than keep a few "bad" ones.

Of the 50 depletion experiments, 24 experiments had estimates for 1 or more of the 4 error terms that fall at or above the 80th percentile. Experiments with estimates for error terms Err1 (Equation 9) and Err2 (Equation 10) at or above the 80th percentile are experiments that differed substantially from the chosen subset of simulations for 1 or more of the 4 characteristics that describe the depletion experiments, the $\mathrm{CV}_{\mathrm{E}}$, the $\mathrm{CV}_{\mathrm{K}}$, the number of tows, and the EAS. These field experiments were not well described by the most similar subset of simulations. The possibility that the range of values for EAS might influence the differential in the results for Err1 and Err2 was tested by recomputing $E r r 2$ by using $\log _{\mathrm{e}}(E A S)$. The set of experiments flagged by $\operatorname{Err} 2$ did not change.

The error terms Err3 (Equation 8) and Err4 (Equation 11) provide an alternate method from $E r r 1$ and $E r r 2$ to identify field experiments that potentially produced unreliable efficiency estimates. In this case, error in efficiency estimates from a subset of similar simulations, each with a known error in their efficiency estimate, were compared. Field experiments most similar to simulated experiments that yielded high values for Err3 and Err4 were flagged.

When field experiments produced parameter estimates that fall at or above the 80th percentile for an error term, they were flagged by that error term (Table 6). When these field experiments were compared with the experiments that produced estimates that fall below the 80th percentile, some differences in Patch model estimates of gear efficiency and clam density came to light, highlighting that the 4 error measures are operationally different and can be used to evaluate experiment performance in different ways. For example, the experiments that were flagged by $\operatorname{Err} 2, \operatorname{Err} 3$, and Err4 produced lower average and median efficiency estimates than those from experiments flagged by Err1.

The relationships between data from the field experiments flagged by one or more error terms and the rest of the data set were evaluated by using Wilcoxon rank sums tests (Table 7). Experiments flagged by Err1 did not differ significantly from the remaining experiments for any of the measured depletion parameters. In each case, the 


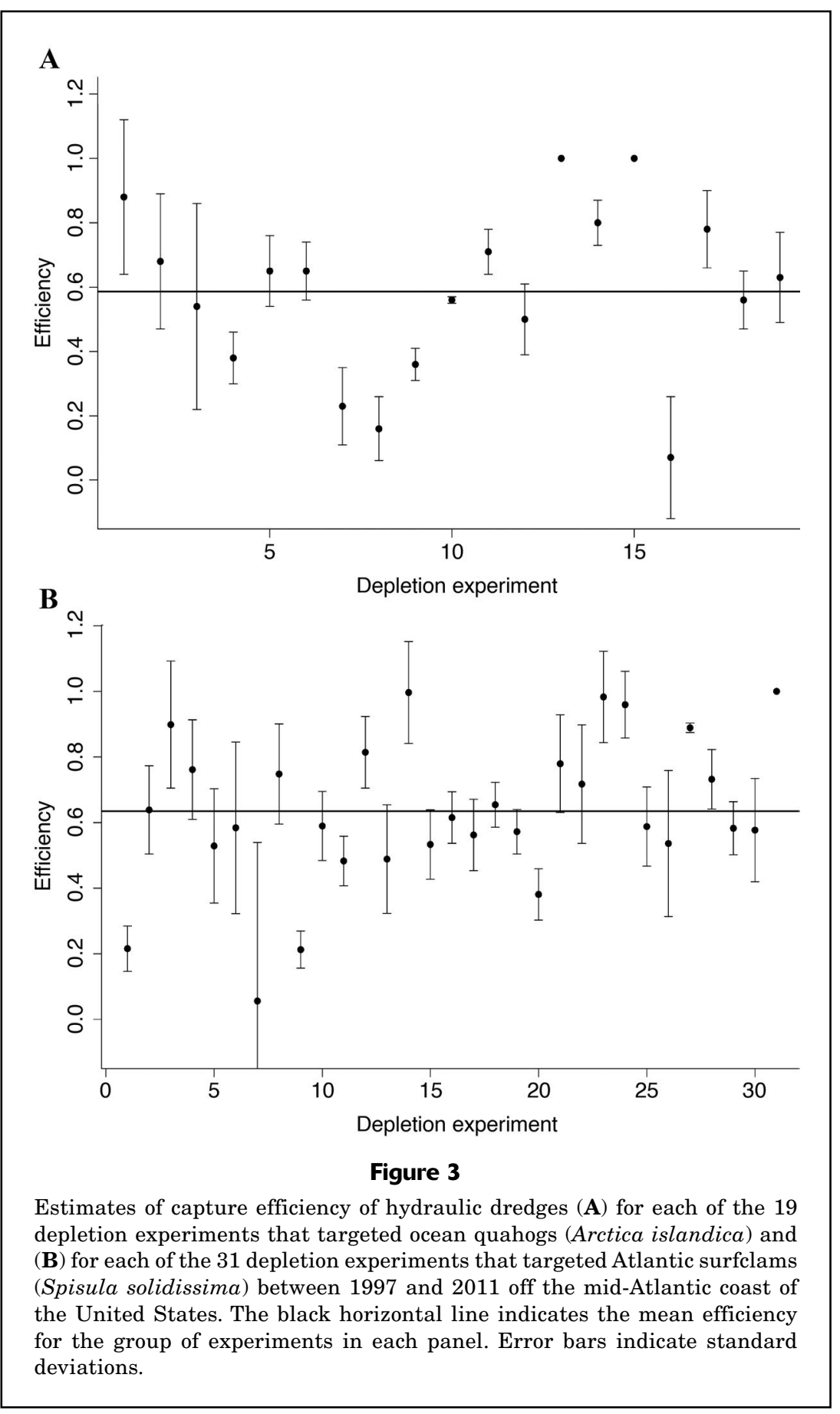

experiments. In addition, experiments flagged by $E r r 3$ and $E r r 4$ had $\mathrm{CV}_{\mathrm{K}}$ and EAS values that were substantially different from the values from the experiments that were not flagged (Table 8). Interestingly, all 9 experiments flagged by $\operatorname{Er} 3$ were among the 10 flagged by Err4, yet experiments flagged by Err3 produced significantly different $\mathrm{CV}_{\mathrm{E}}$ and $\mathrm{CV}_{\mathrm{D}}$ estimates and the group of experiments flagged by $\operatorname{Err} 4$ did not.

\section{Correspondence analysis}

A plot of correspondence analysis shows that variance in descriptor characteristics is primarily explained by the first 2 axes (Fig. 6). The 4 error terms are included as supplementary variables. The dispersions of clams (Fig. 2) were also added as supplementary variables; however, they are not included in the figures because each falls near the center of the correspondence plot. Dimension 1 (Figs. 6 and 7) was determined primarily on the basis of characteristic values from the Patch model, including estimates of efficiency, $\mathrm{CV}_{\mathrm{E}}, \mathrm{CV}_{\mathrm{D}}$, width of the dredge, and EAS (Table 9). Low EAS (which indicates more dredge overlap, low efficiency, or small experimental area), low efficiency estimates, high $\mathrm{CV}_{\mathrm{E}}$ and $\mathrm{CV}_{\mathrm{D}}$, and small dredge sizes $(2.54 \mathrm{~m}[8.33 \mathrm{ft}]$ and $3.05 \mathrm{~m}$ [10.00 ft] wide), along with experiments with estimates of Err2, Err3, and Err4 that fall at or above the 80th percentile, fall on the positive (right) side of dimension 1 . High efficiency estimates, high EAS, the largest dredge size $(3.81 \mathrm{~m}$ [12.50 ft]), and low $\mathrm{CV}_{\mathrm{E}}$ and $\mathrm{CV}_{\mathrm{D}}$ fall on the negative (left) side of dimension 1.

Dimension 2 (Figs. 6 and 7) is categorized by species (the ocean quahog and Atlantic surfclam) and other variables that relate to the location of the depletion experiments for the 2 species, such as depth, latitude, and region. The positive values are variables that relate to depletion experiments that targeted

identified experiments were distributed randomly within the full set of field experiments with respect to the different error terms tested. If the experiments flagged by $\operatorname{Err} 1$ were removed from the analysis, the mean and median efficiency estimates of the remaining field depletion experiments were not significantly different from the mean and median estimates for the entire data set. In dramatic contrast, for experiments flagged by Err2, Err3, and Err4, the efficiency estimates from the Patch model differed substantially from the estimates from the remaining field ocean quahogs, variables such as higher latitudes and deeper depths. Negative values are variables that relate to depletion experiments that targeted Atlantic surfclams: lower latitudes and shallower depths. Experiments with ocean quahogs were typically conducted farther north (Fig. 1) than experiments with Atlantic surfclams, and the species is generally found at deeper depths than the Atlantic surfclam. Dimension 3 (Figs. 7 and 8) is characterized by the $\mathrm{CV}_{\mathrm{K}}$, and high efficiency estimates and high EAS fall on the positive side. 


\section{Table 5}

Characteristics and other details for depletion experiments that were conducted in the field and targeted ocean quahogs (Arctica islandica) and Atlantic surfclams (Spisula solidissima) between 1997 and 2011 off the mid-Atlantic coast of the United States. The regions are Long Island (LI) in New York; New Jersey (NJ); Southern New England (SNE); and the Delmarva Peninsula in Delaware, Maryland, and Virginia. Experiments with an error estimate at or above the 80th percentile are denoted with an asterisk $(*)$ followed by the number of the error term $(1,2,3$, or 4$)$. The overlap score describes the overlap of tows of the dredge in an experiment.

\begin{tabular}{|c|c|c|c|c|c|c|c|}
\hline Experiment ID & Region & $\begin{array}{c}\text { Dredge } \\
\text { width }(\mathrm{m})\end{array}$ & $\begin{array}{l}\text { No. of } \\
\text { tows }\end{array}$ & $\begin{array}{l}\text { Overlap } \\
\text { score }\end{array}$ & Year & Latitude & Longitude \\
\hline $\operatorname{SC} 1997-2(* 3, * 4)$ & NJ & 2.54 & 39 & 0.5237 & 1997 & 40.05317 & -73.83917 \\
\hline SC1997-3 & NJ & 3.30 & 13 & 1.2586 & 1997 & 39.39317 & -73.91033 \\
\hline SC1997-4 (*1) & NJ & 3.30 & 18 & 0.9197 & 1997 & 39.39317 & -73.91033 \\
\hline SC1997-5 & NJ & 2.54 & 17 & 0.7535 & 1997 & 39.36500 & -73.89833 \\
\hline SC1997-6 (*1) & NJ & 2.54 & 19 & 0.6972 & 1997 & 39.36500 & -73.89833 \\
\hline SC1999-2 & NJ & 3.30 & 4 & 1.4151 & 1999 & 39.68133 & -73.74667 \\
\hline SC1999-3 (*2) & NJ & 3.30 & 5 & 1.1389 & 1999 & 39.68133 & -73.74667 \\
\hline SC1999-4 & $\mathrm{NJ}$ & 3.30 & 6 & 1.7098 & 1999 & 39.52133 & -73.77867 \\
\hline SC1999-5 (*1) & DMV & 3.30 & 28 & 0.7257 & 1999 & 36.90200 & -74.97583 \\
\hline SC1999-6 (*2) & NJ & 3.30 & 4 & 1.1338 & 1999 & 39.56333 & -73.91167 \\
\hline SC1999-7 & NJ & 3.30 & 10 & 0.7994 & 1999 & 39.76800 & -73.91633 \\
\hline OQ00-01 (*2) & LI & 3.81 & 22 & 0.6107 & 2000 & 40.60217 & -71.98750 \\
\hline OQ00-02 (*1) & $\mathrm{LI}$ & 3.81 & 16 & 0.6647 & 2000 & 40.39450 & -72.54300 \\
\hline OQ00-03 $(* 2, * 3, * 4)$ & $\mathrm{LI}$ & 3.05 & 27 & 0.4191 & 2000 & 40.58300 & -72.79683 \\
\hline OQ02-01 $(* 3, * 4)$ & LI & 3.05 & 24 & 0.7954 & 2002 & 40.72762 & -71.73730 \\
\hline OQ02-02 & $\mathrm{LI}$ & 3.05 & 22 & 0.6755 & 2002 & 40.10312 & -73.19108 \\
\hline OQ02-03 & NJ & 3.05 & 20 & 0.7304 & 2002 & 38.81491 & -73.81335 \\
\hline OQ02-04 (*3*4) & DMV & 3.05 & 24 & 0.7645 & 2002 & 37.88755 & -74.64486 \\
\hline SC02-02 & NJ & 3.30 & 16 & 0.7788 & 2002 & 40.10908 & -73.84423 \\
\hline SC02-03 $(* 3 * 4)$ & $\mathrm{NJ}$ & 3.30 & 20 & 1.0199 & 2002 & 39.26923 & -73.78116 \\
\hline SC02-04 & DMV & 3.30 & 18 & 0.7992 & 2002 & 38.85791 & -74.02778 \\
\hline SC04-01 & NJ & 3.30 & 24 & 0.9250 & 2004 & 39.28611 & -73.87778 \\
\hline SC04-02 & NJ & 3.30 & 20 & 0.8534 & 2004 & 39.58278 & -74.02778 \\
\hline SC04-03 $(* 1)$ & DMV & 3.05 & 20 & 1.0088 & 2004 & 38.27075 & -74.37920 \\
\hline OQ05-01 $(* 1 * 2 * 3 * 4)$ & LI & 3.05 & 20 & 1.2952 & 2005 & 40.51903 & -72.07617 \\
\hline OQ05-02 $(* 1)$ & $\mathrm{LI}$ & 3.05 & 21 & 1.3401 & 2005 & 40.38957 & -72.38950 \\
\hline OQ05-03 $(* 2 * 3 * 4)$ & $\mathrm{LI}$ & 3.05 & 20 & 1.1380 & 2005 & 40.64220 & -72.65170 \\
\hline OQ05-04 (*2) & $\mathrm{LI}$ & 3.05 & 17 & 1.1259 & 2005 & 40.68170 & -72.18147 \\
\hline OQ05-06 $(* 2 * 3 * 4)$ & $\mathrm{LI}$ & 3.05 & 20 & 1.0803 & 2005 & 40.05550 & -72.41673 \\
\hline SC05-01 & NJ & 3.05 & 20 & 1.1754 & 2005 & 39.26530 & -74.37947 \\
\hline SC05-02 & NJ & 3.05 & 17 & 1.0985 & 2005 & 39.56383 & -73.90364 \\
\hline $\operatorname{SC05-03}(* 1 * 2)$ & $\mathrm{NJ}$ & 3.05 & 20 & 1.0094 & 2005 & 39.89733 & -73.90591 \\
\hline SC05-04 (*3*4) & DMV & 3.05 & 20 & 1.2129 & 2005 & 39.56972 & -73.54946 \\
\hline SC05-05 & NJ & 3.05 & 17 & 1.0779 & 2005 & 39.43615 & -73.37320 \\
\hline OQ08-01 & $\mathrm{LI}$ & 3.05 & 17 & 0.8493 & 2008 & 40.93762 & -72.04765 \\
\hline OQ08-02 & LI & 3.05 & 17 & 0.8783 & 2008 & 40.27445 & -72.84397 \\
\hline OQ08-03 & SNE & 3.81 & 17 & 0.7940 & 2008 & 41.02307 & -70.85472 \\
\hline SC08-01 & $\mathrm{NJ}$ & 3.81 & 13 & 0.8097 & 2008 & 39.30475 & -74.05158 \\
\hline SC08-02 & NJ & 3.81 & 18 & 1.2103 & 2008 & 39.18136 & -74.07645 \\
\hline SC08-03 $(* 1)$ & NJ & 3.81 & 21 & 0.8772 & 2008 & 39.60343 & -73.42194 \\
\hline SC08-04 & $\mathrm{NJ}$ & 3.81 & 17 & 0.9867 & 2008 & 39.81033 & -73.9149 \\
\hline SC08-09 & NJ & 3.81 & 17 & 0.9607 & 2008 & 39.31328 & -74.05285 \\
\hline OQ11-01 (*2) & NJ & 3.81 & 10 & 1.0210 & 2011 & 39.03003 & -74.05774 \\
\hline OQ11-02 & $\mathrm{NJ}$ & 3.81 & 20 & 0.9027 & 2011 & 39.89356 & -73.48104 \\
\hline OQ11-02S & $\mathrm{NJ}$ & 3.81 & 18 & 1.1519 & 2011 & 39.8925 & -73.47500 \\
\hline OQ11-05 & $\mathrm{LI}$ & 3.81 & 22 & 0.9783 & 2011 & 40.13542 & -72.12010 \\
\hline $\mathrm{SC} 11-02(* 4)$ & $\mathrm{NJ}$ & 3.81 & 20 & 0.9027 & 2011 & 39.89356 & -73.48104 \\
\hline SC11-02S & NJ & 3.81 & 18 & 0.9543 & 2011 & 39.89250 & -73.47500 \\
\hline $\operatorname{SC} 11-03(* 1)$ & LI & 3.81 & 14 & 1.0206 & 2011 & 40.56700 & -73.08100 \\
\hline SC11-04 & $\mathrm{LI}$ & 3.81 & 17 & 0.9260 & 2011 & 40.64100 & -73.03600 \\
\hline
\end{tabular}




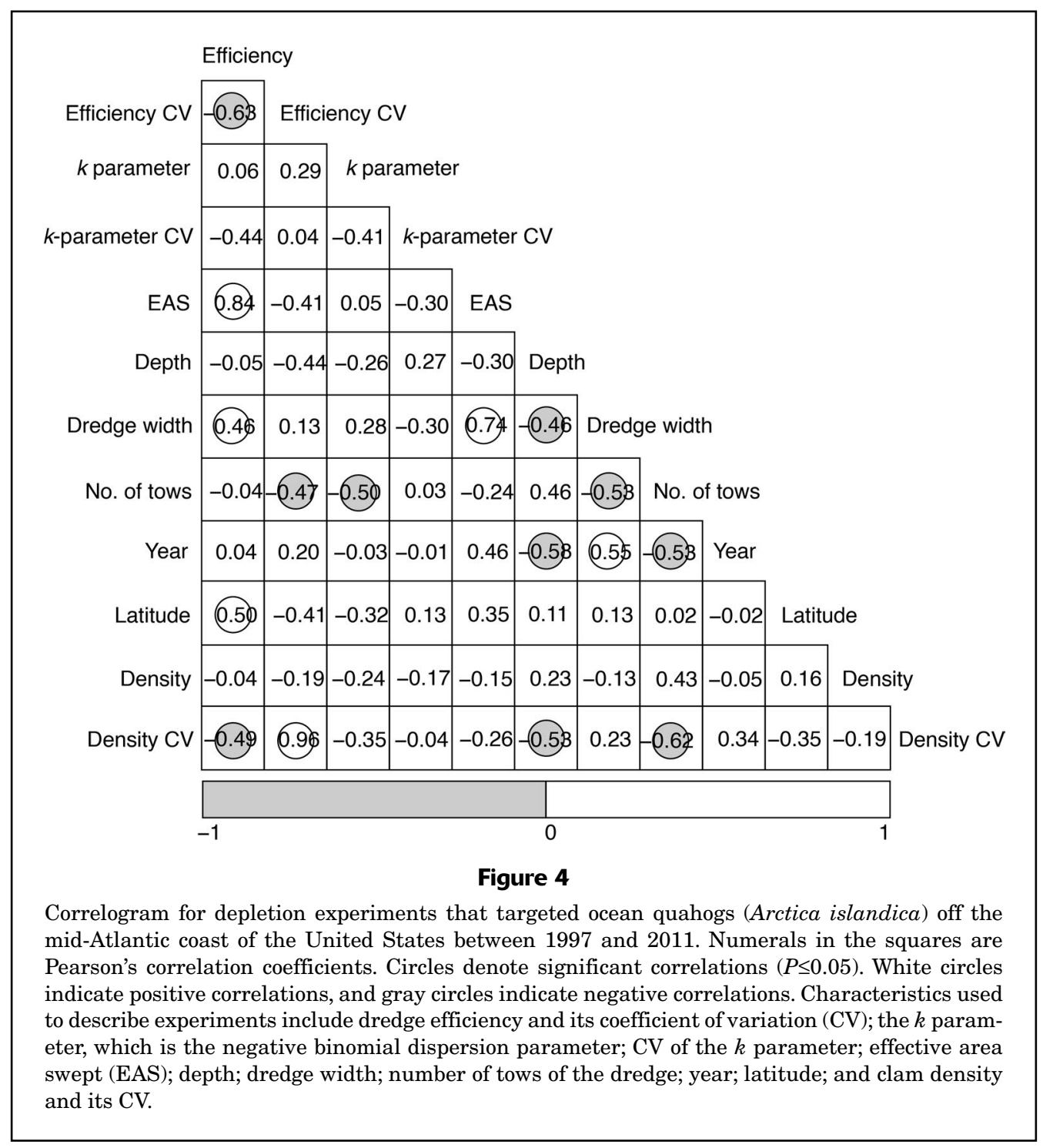

The parameters describing clam distribution do not fall on any axis and are grouped in the middle of the correspondence analysis plots on all dimensions; therefore, they are not included in the figures to improve clarity. Although clam distribution clearly affects the outcome of individual experiments, as observed through simulation analysis (Poussard et al., 2021), this effect is distributed across the experimental spectrum, apportioning uncertainty in a relatively random way with respect to the field experimental data set.

\section{Discussion}

\section{Estimation of efficiency}

The 4 error terms identify field depletion experiments that engender misgivings about their quality. Because the 4 characteristics used to generate 2 of the error estimates (Err1 and Err2), $\mathrm{CV}_{\mathrm{E}}, \mathrm{CV}_{\mathrm{K}}$, OS, and average EAS, are orthogonal to each other, identification of a subset of experiments flagged by Err1 and Err2 indicates that these experiments are characterized by an unusual distribution of these 4 descriptive measures. It is important to note that using a log transformation of EAS did not change which experiments were flagged by these 2 error terms. A close fit to the values of these 4 characteristics was not found among the 9000 simulations of Poussard et al. (2021) that covered a wide range of experimental protocols and field conditions of clam dispersion (Table 1). The absence of a close fit is reason to suspect that these experiments may be uninformative or may have produced inaccurate efficiency estimates.

Error terms Err3 and Err4 relate to inferred inaccuracies in the efficiency estimates, also gleaned from comparison with the simulation data set of Poussard et al. (2021). Experiments flagged by these error terms are most comparable to simulations with high average error 


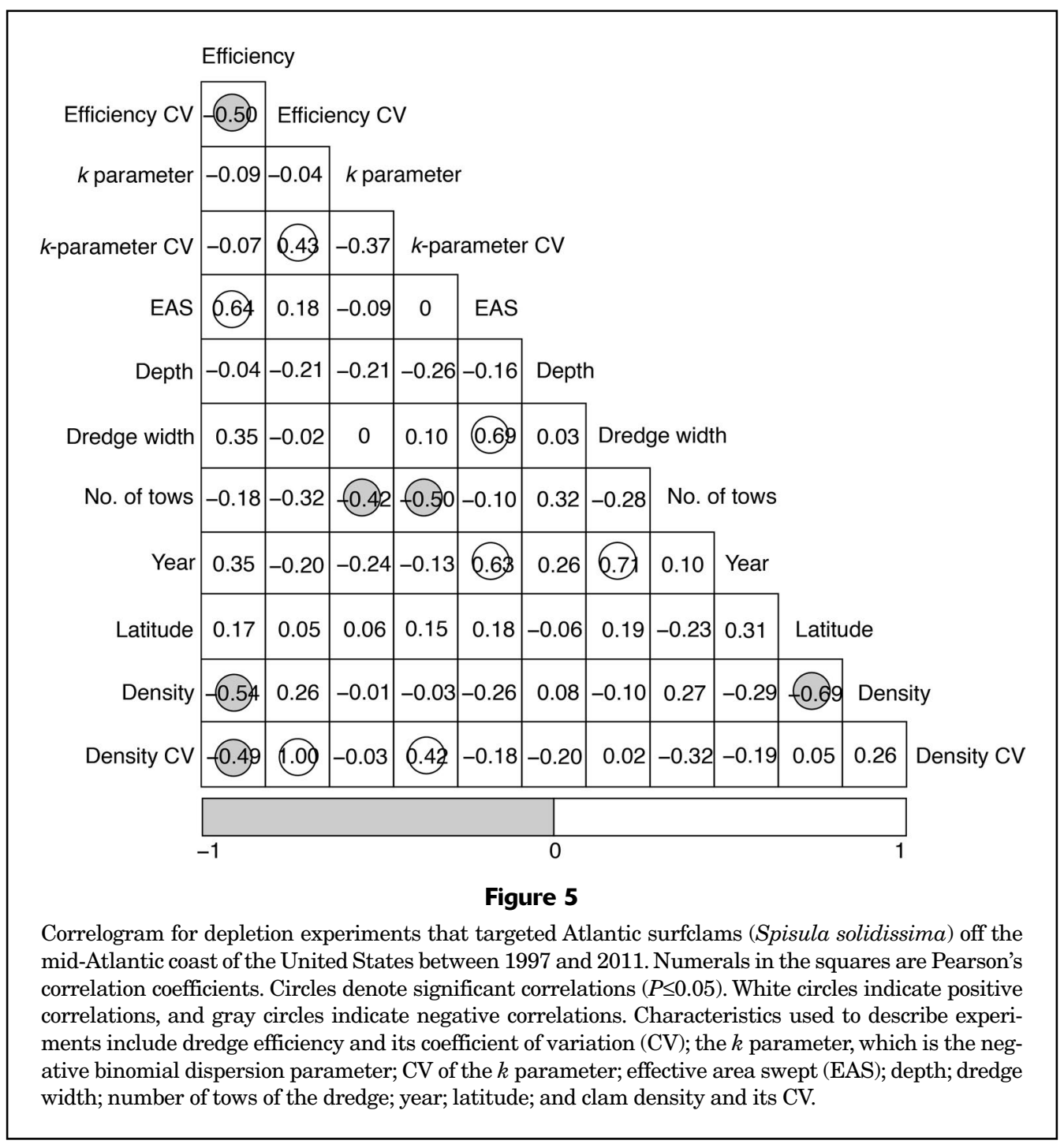

Table 6

Average and median values of the following Patch model parameters for depletion experiments that were flagged because estimates were at or above the 80th percentile for each error term: dredge efficiency; clam density; the $k$ parameter, which is the negative binomial dispersion parameter; effective area swept (EAS); and overlap score (OS), which describes the overlap of tows of the dredge. Standard deviations (SDs) were calculated with the maximum likelihood equation (Equation 5), and CVs were calculated with Equation 6. Data used in the model are from depletion experiments conducted during 1997-2011 for populations of ocean quahogs (Arctica islandica) and Atlantic surfclams (Spisula solidissima) off the mid-Atlantic coast of the United States.

\begin{tabular}{|c|c|c|c|c|c|c|c|c|c|c|c|c|c|}
\hline \multirow{2}{*}{$\begin{array}{l}\text { Error } \\
\text { term }\end{array}$} & \multirow{2}{*}{$\begin{array}{l}\text { Type of } \\
\text { value }\end{array}$} & \multirow{2}{*}{$\begin{array}{c}\text { No. of } \\
\text { flagged } \\
\text { experiments }\end{array}$} & \multicolumn{3}{|c|}{ Efficiency } & \multicolumn{3}{|c|}{$\begin{array}{c}\text { Density } \\
\text { (individuals } / \mathrm{m}^{2} \text { ) }\end{array}$} & \multicolumn{3}{|c|}{$k$ parameter } & \multirow{2}{*}{$\begin{array}{l}\text { EAS } \\
\left(\mathrm{m}^{2}\right)\end{array}$} & \multirow[b]{2}{*}{ OS } \\
\hline & & & Value & $\mathrm{SD}$ & $\mathrm{CV}$ & Value & $\mathrm{SD}$ & $\mathrm{CV}$ & Value & $\mathrm{SD}$ & $\mathrm{CV}$ & & \\
\hline \multirow[t]{2}{*}{ Err1 } & Average & 10 & 0.514 & 0.124 & 26.80 & 2.26 & 0.49 & 214.34 & 5.41 & 2.57 & 88.60 & 99,871 & 0.96 \\
\hline & Median & & 0.567 & 0.115 & 24.06 & 0.67 & 0.13 & 193.92 & 4.52 & 1.99 & 32.24 & 14,196 & 0.96 \\
\hline \multirow[t]{2}{*}{ Err2 } & Average & 10 & 0.464 & 0.171 & 134.74 & 1.36 & 5.82 & 3933.21 & 20.94 & 2.91 & 59.22 & 99,251 & 1.00 \\
\hline & Median & & 0.551 & 0.109 & 25.30 & 0.88 & 0.23 & 189.55 & 6.68 & 2.24 & 31.95 & 10,666 & 1.10 \\
\hline \multirow[t]{2}{*}{ Err3 } & Average & 9 & 0.384 & 0.106 & 34.09 & 1.51 & 0.36 & 292.30 & 5.30 & 2.10 & 58.50 & 6584 & 0.92 \\
\hline & Median & & 0.381 & 0.103 & 32.08 & 0.97 & 0.36 & 238.35 & 4.45 & 1.58 & 29.87 & 6302 & 1.02 \\
\hline \multirow[t]{2}{*}{ Err4 } & Average & 10 & 0.419 & 0.104 & 31.92 & 1.15 & 0.33 & 273.36 & 5.34 & 2.07 & 55.78 & 8134 & 0.92 \\
\hline & Median & & 0.435 & 0.097 & 27.39 & 0.92 & 0.32 & 205.66 & 5.07 & 1.62 & 29.91 & 6400 & 0.96 \\
\hline
\end{tabular}




\section{Table 7}

Results of Wilcoxon rank sums tests for depletion experiment variables classified by error terms. Experiments were flagged because estimates of variables were at or above the 80th percentile for one or more error terms. The tests were used to evaluate relationships between data from the field experiments flagged by one or more error terms with the rest of the data set from experiments conducted during 1997-2011 for ocean quahogs (Arctica islandica) and Atlantic surfclams (Spisula solidissima) off the mid-Atlantic coast of the United States. A dash indicates that the relationship between an error term and a variable are not significant $(P>0.05)$. Variables that describe the experiments include dredge efficiency; clam density; the $k$ parameter, which is the negative binomial dispersion parameter; effective area swept (EAS); and number of tows of the dredge. $\mathrm{CV}=$ coefficient of variation.

\begin{tabular}{lcccc}
\hline & \multicolumn{5}{c}{$P>|Z|$} \\
\cline { 2 - 5 } & \multicolumn{5}{c}{ Error term } \\
\cline { 2 - 5 } Variable & Err1 & Err2 & Err3 & Err4 \\
\hline Efficiency & - & 0.0454 & 0.0004 & 0.0014 \\
Efficiency CV & - & - & 0.0180 & - \\
Density & - & - & - & - \\
Density CV & - & - & 0.0250 & - \\
$k$ parameter & - & - & - & - \\
$k$-parameter CV & - & - & 0.0340 & 0.0250 \\
EAS & - & - & 0.0001 & 0.0009 \\
No. of tows & - & - & - & - \\
& & &
\end{tabular}

in efficiency estimates and potentially have high average error in efficiency themselves. Nine out of 10 experiments flagged by $E r r 4$ were also flagged by $E r r 3$, as these 2 error terms are very similar. These experiments may be uninformative or may have produced inaccurate efficiency estimates.

Ultimately, because of the nature of the error terms and the inability to evaluate all possible experimental conditions (e.g., all possible tow numbers and clam distributions, or all possible true efficiencies), the inference that the flagged experiments produced uninformative or inaccurate efficiency estimates cannot be affirmed. In aggregate, however, the analysis of the field experiments points to a subset of field experiments of lower quality than the remainder.

Interestingly, the experiments flagged by Err1, which might identify suspect experiments, exert less influence on the final objective of determining the efficiency of hydraulic dredges. The distribution of these experiments is unbiased relative to the remaining experiments, regardless of the characteristic used for comparison (Table 5). The same cannot be said for Err2, Err3, and Err4. The series of 16 depletion experiments with estimates of Err2, Err3, and Err4 that fall at or above the 80th percentile is clearly biased relative to the remaining experiments, on the basis of the results of Wilcoxon rank sums tests (Table 7), and the existence of this bias is reinforced by correspondence analysis (Figs. 6-8). In addition, the direction of bias is noteworthy. Experiments identified by Err2, Err3, and Err4 are characterized by lower efficiency estimates on

\section{Table 8}

Comparison of mean and median values of model parameters between depletion experiments with parameter estimates at or above the 80th percentile for error terms Err2, Err3, and Err4 and experiments with estimates below the 80th percentile for the same error terms. The parameters are dredge efficiency and its coefficient of variation (CV); the CV of the $k$ parameter, which is the negative binomial dispersion parameter; clam density and its CV; overlap score (OS), which describes the overlap of tows of the dredge; and effective area swept (EAS). Data used in the model are from depletion experiments conducted during 1997-2011 for populations of ocean quahogs (Arctica islandica) and Atlantic surfclams (Spisula solidissima) off the mid-Atlantic coast of the United States.

\begin{tabular}{|c|c|c|c|c|c|c|c|}
\hline \multirow[b]{3}{*}{ Parameter } & \multirow[b]{3}{*}{$\begin{array}{l}\text { Type of } \\
\text { value }\end{array}$} & \multicolumn{6}{|c|}{ Error term } \\
\hline & & \multicolumn{2}{|c|}{ Err2 } & \multicolumn{2}{|c|}{ Err3 } & \multicolumn{2}{|c|}{ Err4 } \\
\hline & & $\begin{array}{c}<80 \text { th } \\
\text { percentile }\end{array}$ & $\begin{array}{c}\geq 80 \text { th } \\
\text { percentile }\end{array}$ & $\begin{array}{c}<80 \text { th } \\
\text { percentile }\end{array}$ & $\begin{array}{c}\geq 80 \text { th } \\
\text { percentile }\end{array}$ & $\begin{array}{c}<80 \text { th } \\
\text { percentile }\end{array}$ & $\begin{array}{c}\geq 80 \text { th } \\
\text { percentile }\end{array}$ \\
\hline \multirow[t]{2}{*}{ Efficiency } & Mean & 0.654 & 0.464 & 0.667 & 0.384 & 0.666 & 0.419 \\
\hline & Median & 0.645 & 0.551 & 0.652 & 0.381 & 0.652 & 0.435 \\
\hline \multirow[t]{2}{*}{ Efficiency CV } & Mean & 19.496 & 134.744 & 44.402 & 34.089 & 45.202 & 31.920 \\
\hline & Median & 19.232 & 25.299 & 16.789 & 32.075 & 17.325 & 27.392 \\
\hline \multirow[t]{2}{*}{$k$-parameter $\mathrm{CV}$} & Mean & 41.785 & 59.215 & 42.368 & 58.497 & 42.644 & 55.783 \\
\hline & Median & 32.924 & 31.953 & 33.139 & 29.869 & 33.257 & 29.913 \\
\hline \multirow[t]{2}{*}{ Density (individuals $/ \mathrm{m}^{2}$ ) } & Mean & 1.389 & 1.356 & 1.345 & 1.507 & 1.367 & 1.421 \\
\hline & Median & 0.743 & 0.887 & 0.743 & 0.969 & 0.743 & 0.915 \\
\hline \multirow[t]{2}{*}{ Density CV } & Mean & 162.998 & 3933.081 & 1054.153 & 292.294 & 1077.931 & 273.350 \\
\hline & Median & 135.765 & 189.542 & 132.375 & 238.345 & 132.924 & 205.655 \\
\hline \multirow[t]{2}{*}{ OS } & Mean & 0.948 & 0.997 & 0.967 & 0.917 & 0.969 & 0.915 \\
\hline & Median & 0.911 & 1.103 & 0.926 & 1.020 & 0.940 & 0.961 \\
\hline \multirow[t]{2}{*}{$\operatorname{EAS}\left(\mathrm{m}^{2}\right)$} & Mean & $18,048.6$ & $99,251.5$ & $40,370.7$ & 6584.3 & $40,827.9$ & 8134.3 \\
\hline & Median & $15,489.3$ & $10,666.3$ & $16,066.2$ & 6302.6 & $16,050.7$ & 6400.2 \\
\hline
\end{tabular}




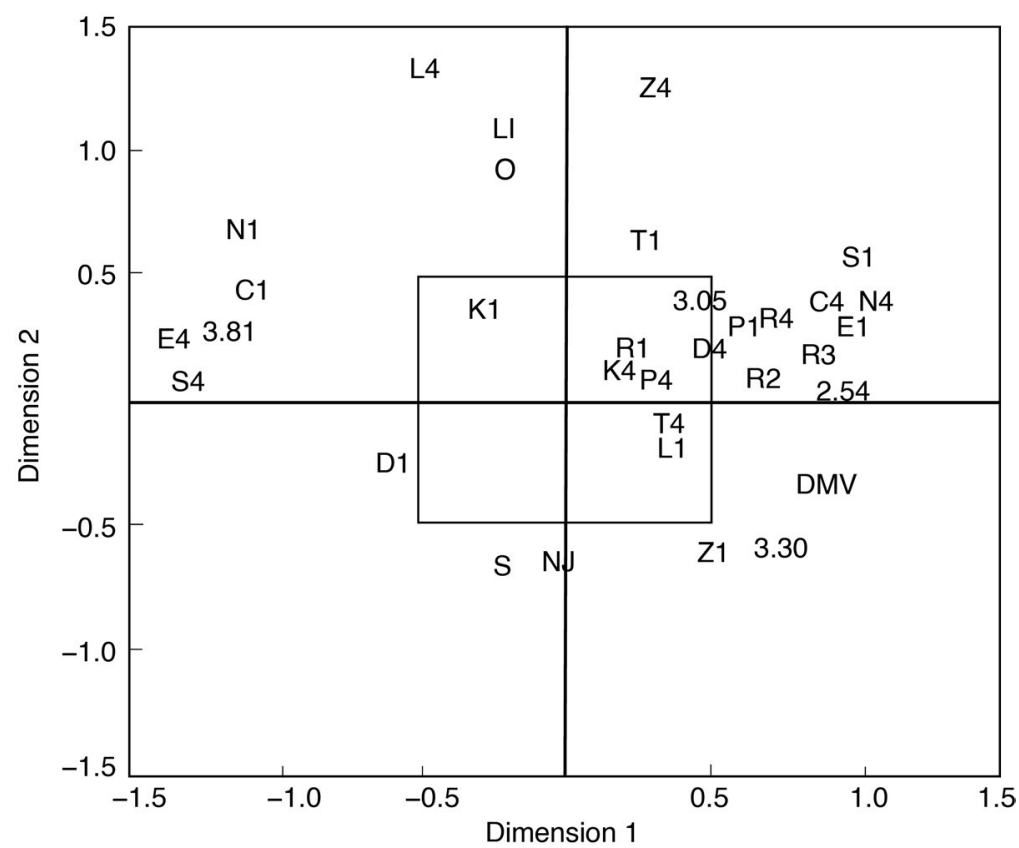

Figure 6

Correspondence analysis for dimensions 1 and 2 for the data set from depletion experiments conducted during 1997-2011 to examine efficiency of hydraulic dredges for capturing clam species and to estimate stock density for populations of ocean quahogs (Arctica islandica) and Atlantic surfclams (Spisula solidissima) off the mid-Atlantic coast of the United States. Error terms $\operatorname{Err} 1$ (R1), Err2 (R2), Err3 (R3), and Err4 (R4) are supplementary variables. Estimates of the following characteristics are entered as quartiles: dredge efficiency (E); clam density (D); the $k$ parameter (K), which is the negative binomial dispersion parameter; coefficient of variation (CV) of efficiency (C); CV of density (N); CV of the $k$ parameter (P); effective area swept (S); overlap score (T); latitude (L); and depth (Z); only quartiles 1 and 4 are shown in the plot. Other variables that describe the experiments include species, the ocean quahog $(\mathrm{O})$ and Atlantic surfclam (S); region, Long Island (LI) in New York, New Jersey (NJ), and the Delmarva Peninsula (DMV) of Delaware, Maryland, and Virginia; and dredge width. Dredge widths are 2.54, $3.05,3.30$, and $3.81 \mathrm{~m}$. Error estimates are entered as 1 (below the 80th percentile) or 2 (at or above the 80th percentile). The inner box demarcates the area with loading factors from -0.5 to 0.5 on both axes.

dredge width (3.81 m [12.5 ft]); experiments with dredges of this size clearly had superior performance.

High OS in a depletion experiment does not always reduce uncertainty in Patch model estimates. An explanation for this may come from the pragmatic efforts of a field experiment. Depletion experiments are costly in vessel time and crew effort, often requiring more than $8 \mathrm{~h}$ of nearly continual dredging. Cost at sea was sufficient in that adaptive time management during the experiment was directed at limiting tow number, albeit with limited empirical guidance to determine the stopping point for the depletion experiment.

One consequence of adaptive time management during the depletion experiment was a decision to add tows if the experiment appeared not to be generating a clear and consistent reduction in catch per tow. Results of correspondence analysis indicate the danger of the use of adaptive decisions during depletion experiments without rigorous empirical determination criteria designed to optimize the cost and benefit of increasing tow number. The danger of terminating a depletion experiment early on the basis of a potentially misleading depletion curve was present as well. The OS did not fall out cleanly in any of the dimensions on the plots of correspondence analysis, the opposite of what was expected given the clear improvement afforded by higher tow numbers, and more tow overlap, in the simulation study of Poussard et al. (2021). However, the absence of OS did not diminish its effect on estimates of gear efficiency in depletion experiments. Notably, OS and the distribution of clams on the bottom (e.g., NP, P, T, or HP), which in some fashion are measures of dredge

average, and their inclusion in the depletion data set may bias the overall efficiency estimates used to inform stock assessments.

In correspondence analysis, Err2, Err3, and Err4 also fall on the same dimensional axis as a low EAS value. Low EAS and low efficiency generally occur together because the efficiency value is a variable in the equation determining EAS (Equation 3). The relationship is well-documented by Poussard et al. (2021). This expectation is confirmed by Pearson's correlation coefficients calculated by using the field depletion experiment data set (Figs. 4 and 5). The EAS is also positively correlated with year for experiments that targeted ocean quahogs and with dredge width for experiments with both ocean quahogs and Atlantic surfclams (Figs. 4 and 5). The relationship is driven by the largest overlap with tow paths or with clams in the area, are both relatively unbiased parameters. That is, they are not associated with any depth, dredge size, species, or other characteristic of the experiment. The distribution of clams relative to the distribution of tows is a critical constraint on efficiency estimation.

Results of correspondence analysis clearly reveal the relationships earlier identified by using the Wilcoxon rank sum tests and by Pearson's correlation coefficients. The error terms Err2, Err3 and Err4, which the results of Wilcoxon analyses indicate were highly significant, fall on the positive side of dimension 1 along with the parameters and experiment characteristics significantly influenced by them. The error term Err1, which did not have significant differences in the Wilcoxon rank sum tests, 


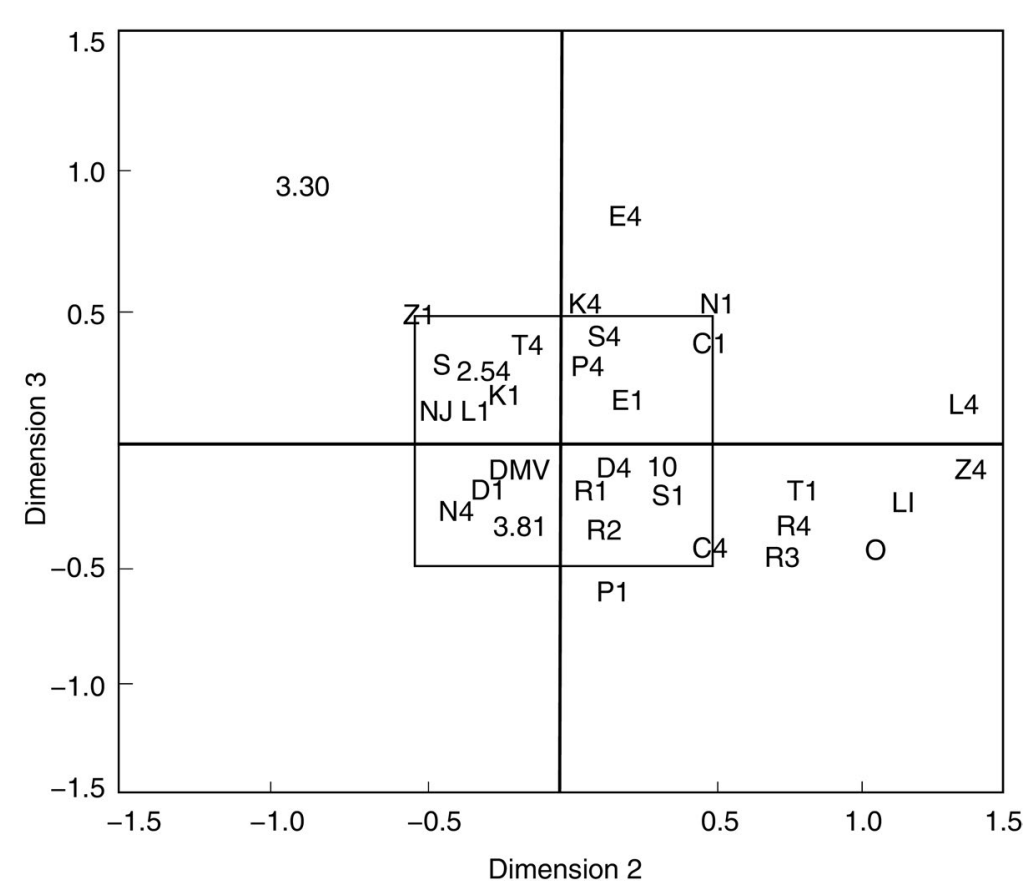

Figure 7

Correspondence analysis for dimensions 2 and 3 for the data set from depletion experiments conducted during 1997-2011 to examine efficiency of hydraulic dredges for capturing clam species and to estimate stock density for populations of ocean quahogs (Arctica islandica) and Atlantic surfclams (Spisula solidissima) off the mid-Atlantic coast of the United States. Error terms Err1 (R1), Err2 (R2), Err3 (R3), and Err4 (R4) are supplementary variables. Estimates of the following characteristics are entered as quartiles: dredge efficiency (E); clam density (D); the $k$ parameter $(\mathrm{K})$, which is the negative binomial dispersion parameter; coefficient of variation (CV) of efficiency (C); CV of density (N); CV of the $k$ parameter (P); effective area swept (S); overlap score (T); latitude (L); and depth (Z); only quartiles 1 and 4 are shown in the plot. Other variables that describe the experiments include species, the ocean quahog (O) and Atlantic surfclam (S); region, Long Island (LI) in New York, New Jersey (NJ), and the Delmarva Peninsula (DMV) of Delaware, Maryland, and Virginia; and dredge width. Dredge widths are 2.54, 3.30, and $3.81 \mathrm{~m}$. Error estimates are entered as 1 (below the 80th percentile) or 2 (at or above the 80 th percentile). The inner box demarcates the area with loading factors from -0.5 to 0.5 on both axes.

similarity in efficiency estimates for the 2 species, which essentially are separated solely by depth.

In the correspondence analysis, Err2, Err3, and Err4 are associated with experiments characterized by smaller dredges, higher $\mathrm{CV}_{\mathrm{E}}$ values, and higher $\mathrm{CV}_{\mathrm{D}}$ values than those of other experiments. The co-occurrence of these characteristics instills suspicion about the quality of the results obtained from a subset of the depletion experiments. Essentially, experiments with estimates of Err2, Err3, and Err4 that fall at or above the 80th percentile produced low efficiency estimates. Experiments most similar to simulations with high average error in efficiency estimates were flagged by $E r r 3$ and Err4, indicating that these experiments could have high uncertainty in efficiency estimates and that these experiments should be removed from further evaluation of the inherent efficiency of hydraulic clam dredges.

\section{Estimation of density}

Interestingly, experiments with high $\mathrm{CV}_{\mathrm{D}}$ are grouped with the experiments with low efficiency identified by Err2, Err3, and Err4 in the correspondence analysis, indicating that experiments with more uncertain estimates of clam density also produced low efficiency estimates and were flagged by the error terms. Poussard et al. (2021) clearly showed that the accuracy of efficiency estimates and the density of clams in the area are not correlated in simulated depletion experiments, save for instances where low clam density combines with an irregular distribution of clams in the benthos to bias efficiency to a low value. Efficiency estimates not being influenced heavily

falls near the origin in all 3 dimensions, indicating that the experiments identified by this error estimate are more or less randomly distributed throughout the field depletion data set. A tendency for large dredges to be associated with improved experimental performance is shown in Figure 6; however, the influence of dredge size is complex, as the various dredge sizes do not fall in order of size on dimensions 1 or 2 . Dredge size to some extent is likely conflated with other variables, such as species, year, and depth, and was determined more by boat availability and increased familiarity of the crew and scientific staff with depletion experiment methods over time than by experiment performance; the clear exception is the largest dredge size. The fact that species as a variable falls near the origin on dimensions 1 and 3 indicates the by clam density is a logical outcome on the basis of an expectation that hydraulic dredges should be equally efficient whether used in low-density or high-density regions. The apposition of high CV for the density estimate and low efficiency is likely a product of high uncertainty in the density estimate co-occurring with high uncertainty in the efficiency estimate. Uncertainties in the efficiency and density estimates could be indicative of an experimental design failing or of environmental parameters not being conducive to accurate and precise estimation of efficiency and density.

The accuracy of the density estimate from the Patch model was evaluated thoroughly in Hennen et al. (2012). The $k$ parameter was not evaluated for accuracy in that study because a negative binomial distribution was not 


\section{Table 9}

Variables that fall on each of the 3 dimensions of correspondence analysis with loading factors $\leq-0.5$ or $\geq 0.5$. Variables describe depletion experiments conducted during 1997-2011 to examine efficiency of hydraulic dredges for capturing clam species and to estimate stock density for populations of ocean quahogs (Arctica islandica) and Atlantic surfclams (Spisula solidissima) off the mid-Atlantic coast of the United States. Variables include dredge width; dredge efficiency and its coefficient of variation (CV); effective area swept (EAS); CV of the $k$ parameter, which is the negative binomial dispersion parameter; error terms Err2, Err3, and Err4; CV of clam density; region, Long Island (LI) in New York, New Jersey (NJ), or the Delmarva Peninsula (DMV) of Delaware, Maryland, and Virginia; overlap score (OS), which describes the overlap of tows of the dredge; species; and latitude. N/A indicates that the variable fell close to the origin and not strongly on the positive or negative side of the dimension.

\begin{tabular}{|c|c|c|c|c|c|c|c|c|}
\hline \multicolumn{3}{|c|}{ Dimension 1} & \multicolumn{3}{|c|}{ Dimension 2} & \multicolumn{3}{|c|}{ Dimension 3} \\
\hline Variable & $\begin{array}{c}\text { Negative } \\
(\leq-0.5)\end{array}$ & $\begin{array}{c}\text { Positive } \\
(\geq 0.5)\end{array}$ & Variable & $\begin{array}{c}\text { Negative } \\
(\leq-0.5)\end{array}$ & $\begin{array}{c}\text { Positive } \\
(\geq 0.5)\end{array}$ & Variable & $\begin{array}{c}\text { Negative } \\
(\leq-0.5)\end{array}$ & $\begin{array}{c}\text { Positive } \\
(\geq 0.5)\end{array}$ \\
\hline Dredge width $(\mathrm{m})$ & 3.81 & $2.54,3.30$ & Dredge width & 3.30 & N/A & Dredge width & 3.30 & N/A \\
\hline Efficiency & High & Low & OS & N/A & Low & Efficiency & N/A & High \\
\hline Efficiency CV & Low & High & Species & $\begin{array}{l}\text { Atlantic } \\
\text { surfclam }\end{array}$ & $\begin{array}{c}\text { Ocean } \\
\text { quahog }\end{array}$ & EAS & N/A & High \\
\hline EAS & High & Low & EAS & N/A & Low & $k$-parameter CV & High & N/A \\
\hline$k$-parameter CV & N/A & Low & Region & NJ & LI & & & \\
\hline $\operatorname{Err} 2, \operatorname{Err} 3$, and $\operatorname{Err} 4$ & N/A & High & Depth & Low & High & & & \\
\hline Density CV & Low & High & Latitude & N/A & High & & & \\
\hline Region & N/A & DMV & Density CV & N/A & Low & & & \\
\hline
\end{tabular}

used to create the distribution of clams. The $k$ parameter is indirectly related to clam distribution and tow distance (Hennen et al., 2012). Results from the simulations of Poussard et al. (2021) indicate that the estimates of $k$ are higher with a uniform distribution of clams and lower with a more irregular distribution. This parameter is influenced by the same conditions of the experiment that influence efficiency, but correspondence analysis does not cleanly separate the $k$ parameter or its CV from other variables, such as the efficiency estimate, density estimate, depth, region, dredge width, and the values of $\mathrm{CV}_{\mathrm{E}}$ and $\mathrm{CV}_{\mathrm{D}}$. (Figs. 7 and 8). The results of correspondence analysis identify a tendency for low uncertainty in the $k$ parameter (and in $\mathrm{CV}_{\mathrm{K}}$ ) to be associated with low efficiency and high $\mathrm{CV}_{\mathrm{E}}$ in comparison with those of other experiments. Experiments with these characteristics also were flagged by the error terms.

Poussard et al. (2021) reported that the dispersion of clams on the bottom clearly can cause a decrease in performance in the depletion experiment. This outcome is exacerbated by low tow number and low amount of tow overlap. In practice, even an ideal experiment, with many dredge tows and a high degree of overlap in the tow paths, would appear to be susceptible to producing an unreliable efficiency estimate if the distribution of clams in the benthos is irregular. Clam dispersion is a random effect for the field experiments, despite its documented importance in determining outcomes. This notion is consistent with the fact that the locations for the experiments were chosen without any a priori knowledge of the characteristics of clam dispersion at the site. As Hennen et al. (2012) concluded, the ability to have divers determine or to use remote optical methods to determine the size, location, and approximate density of clam aggregations would be useful in choosing the site and tow pattern in a depletion experiment.

\section{Factors affecting field outcomes}

The size of the dredge is related to the efficiency estimated, with larger dredges being used with experiments with higher efficiency estimates. Small dredge sizes $(2.54 \mathrm{~m}[8.33 \mathrm{ft}]$ and $3.05 \mathrm{~m}$ [10.00 ft]) were used in many experiments, and they contributed disproportionately to the subset identified by estimates of Err2, Err3, and Err4 (Fig. 6). It may be that smaller dredges are harder to control precisely, leading to greater uncertainty in the exact position of the dredge, uncertainty that can lead to error in the estimation of efficiency (Hennen et al., 2012; Willberg et al., 2013). The majority of flagged experiments identified by estimates of the 4 error terms were conducted in 1997, 1999, and 2005, and among these experiments are those categorized as having lower efficiency estimates with more uncertainty in the estimate, relative to those of the other experiments. Although speculative, 2 possibilities may explain this trend. A wider dredge may be inherently more efficient because loss in efficiency is likely associated with the encounter of clams near the lateral edges of the dredge knife blade, and these clams are a lower fraction of the potential catch with the larger dredge. In addition, the narrow dimension of the depletion rectangle was generally set at 10 dredge widths; therefore, the largest dredge $(3.81 \mathrm{~m}$ [12.50 ft]) was used to deplete larger regions, possibly reducing the influence of smallscale variations in clam dispersion within the depletion rectangle. It is noteworthy that experiments with the 


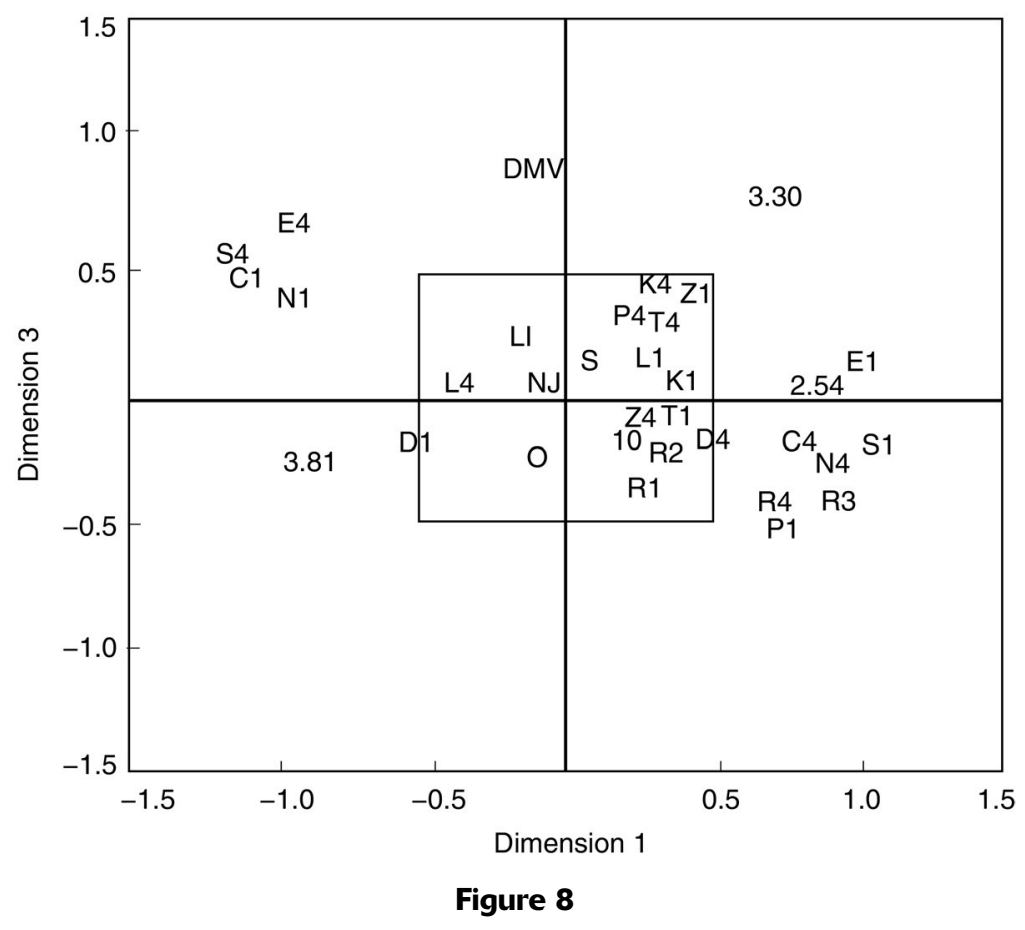

Correspondence analysis for dimensions 1 and 3 for the data set from depletion experiments conducted during 1997-2011 to examine efficiency of hydraulic dredges for capturing clam species and to estimate stock density for populations of ocean quahogs (Arctica islandica) and Atlantic surfclams (Spisula solidissima) off the mid-Atlantic coast of the United States. Error terms Err1 (R1), Err2 (R2), Err3 (R3), and Err4 (R4) are supplementary variables. Estimates of the following characteristics are entered as quartiles: dredge efficiency (E); clam density (D); the $k$ parameter $(\mathrm{K})$, which is the negative binomial dispersion parameter; coefficient of variation (CV) of efficiency (C); $\mathrm{CV}$ of density (N); CV of the $k$ parameter (P); effective area swept (S); overlap score (T); latitude (L); and depth (Z); only quartiles 1 and 4 are shown in the plot. Other variables that describe the experiments include species, the ocean quahog (O) and Atlantic surfclam (S); region, Long Island (LI) in New York, New Jersey (NJ), and the Delmarva Peninsula (DMV) of Delaware, Maryland, and Virginia; and dredge width. Dredge widths are 2.54, 3.30, and $3.81 \mathrm{~m}$. Error estimates are entered as 1 (below the 80th percentile) or 2 (at or above the 80 th percentile). The inner box demarcates the area with loading factors from -0.5 to 0.5 on both axes.

surfclams that took place farther south (Fig. 1). The relationship is not associated with dredge width, although efficiency and dredge width are significantly correlated for experiments with ocean quahogs (Fig. 4). These experiments took place in deeper water, on the average, but correlation and correspondence analysis agree that depth, per se, does not influence outcomes. Edaphic factors may be examined as proxies for the influence of region, but little information is available to make a determination.

Depth might be considered to be an effective variable that determines the success of a depletion experiment for hydraulic dredges because these dredges are operated by using an onboard water pump attached to the dredge by means of a large hose. The vessel is less maneuverable in deeper water because of the increased amount of hose required to maintain an adequate scope while dredging. Surprisingly, neither correlation analysis nor correspondence analysis offer any evidence for a significant correlation between depth and experimental performance or the final efficiency estimate. Depth-related variables, in fact, fall orthogonally to experiment performance characteristics and estimates of the error terms Err2, Err3, and Err4 in correspondence analysis.

\section{Conclusions}

When the 16 experiments (7 experiments with Atlantic surfclams and 9 experiments with ocean quahogs) that had estimates of error terms Err2, Err3 and Err4 that fall at or above the 80th percentile were removed from the field depletion data set, the mean efficiency

largest dredge were conducted in later years, when the depletion experiment method was more consistent among experiments and produced higher efficiency estimates, yielding higher OS values. Accordingly, the improved performance cannot unequivocally be assigned to the largest size of the dredge used.

Location of the depletion experiment might also have affected the efficiency estimate. Depletion experiments that targeted ocean quahogs off Long Island have higher efficiency estimates than experiments conducted farther south. The relationship is shown objectively (Fig. 1) and in correlation (Fig. 4). Results of the correlation analysis do not indicate a significant relationship between latitude and the efficiency estimate, but this finding accrues from the inclusion of high-efficiency experiments with Atlantic estimate increased from 0.635 to 0.694 for experiments that targeted Atlantic surfclams (Table 10). The median likewise rose substantially from 0.590 to 0.647 and the interquartile range, although remaining relatively unchanged in dimension, shifted to higher efficiency values. The mean efficiency estimate for experiments that targeted ocean quahogs increased from 0.586 to 0.711 , and the median rose from 0.629 to 0.667 . The interquartile range was substantially reduced in dimension and shifted to higher efficiency values. The efficiency estimates for the data set after removal of experiments flagged by an error term indicate that experiments flagged by $\operatorname{Err} 1$ do not have efficiency estimates that are biased in either direction and do not meaningfully negate the trends established with the other 3 error terms. 


\section{Table 10}

Comparison of mean, standard deviation (SD), and median values and quartiles of model estimates of dredge efficiency between all depletion experiments and subsets of experiments flagged by all error terms or by error terms Err2, Err3, and Err4. Experiments were flagged because estimates were at or above the 80th percentile for an error term. Data used in the model are from depletion experiments conducted during 1997-2011 for populations of ocean quahogs (Arctica islandica) and Atlantic surfclams (Spisula solidissima) off the mid-Atlantic coast of the United States.

\begin{tabular}{|c|c|c|c|c|c|c|}
\hline Species & Efficiency estimate & Mean & SD & $\begin{array}{c}\text { 1st } \\
\text { quartile }\end{array}$ & Median & $\begin{array}{c}\text { 3rd } \\
\text { quartile }\end{array}$ \\
\hline \multirow{3}{*}{$\begin{array}{l}\text { Ocean } \\
\text { quahog }\end{array}$} & All experiments & 0.586 & 0.260 & 0.381 & 0.629 & 0.779 \\
\hline & 9 experiments flagged by error terms 2,3 , and 4 removed & 0.711 & 0.195 & 0.629 & 0.667 & 0.795 \\
\hline & 10 experiments flagged by all error terms removed & 0.758 & 0.169 & 0.641 & 0.716 & 0.898 \\
\hline \multirow{3}{*}{$\begin{array}{l}\text { Atlantic } \\
\text { surfclam }\end{array}$} & All experiments & 0.635 & 0.229 & 0.533 & 0.590 & 0.779 \\
\hline & 7 experiments flagged by error terms 2,3 , and 4 removed & 0.694 & 0.196 & 0.570 & 0.647 & 0.852 \\
\hline & 13 experiments flagged by all error terms removed & 0.738 & 0.172 & 0.584 & 0.733 & 0.889 \\
\hline
\end{tabular}

Interestingly, the mean and median efficiency estimates for the hydraulic dredges that targeted Atlantic surfclams and ocean quahogs are nearly identical. Neither the species nor the presence of one generally in deeper water than the other significantly influences the overall efficiency that stands at approximately $70 \%$ regardless of mean or median determination.

The analyses of this study permit the evaluation of the factors involved in defining a standard operating protocol for experiments of this kind that are inherently extremely expensive to conduct. Several characteristics that define the success of the experimental design, such as the dispersion of clams on the bottom, will likely be unknown. As a consequence of the uncertainty behind these experiments, a sufficient number of replicates will always be required in order to provide a useful recommendation for catchability. Effectively the same conclusion was made in other studies of dredge calibration with a significant number of experiments (Hennen et al., 2012; Morson et al., 2018).

Estimates from the Patch model are useful in development of stock assessment models in the future; for example, capture efficiency estimates can be used to form prior distributions for catchability parameters (NEFSC, 2010a, 2010b). However, these estimates are only as useful as the data from the depletion experiments used to inform the Patch model. Three groups of experiments have significantly different efficiency estimates and CVs from the remainder, as indicated by results of the Wilcoxon rank sums tests conducted on efficiency estimates flagged by Err2, Err3, and Err4. Although these error estimates can be used only to infer experimental quality, they identify experiments with a range of questionable attributes that strongly implicate them as outliers biasing the efficiency estimates for the entire data set. Removing these questionable experiments from the NMFS depletion data set provided the best estimates of efficiency for these commercial hydraulic dredges, and the results of the removal indicate that these dredges are highly efficient and minimize the degree of bottom contact relative to the catch.

\section{Acknowledgments}

This research was supported by the Science Center for Marine Fisheries, an Industry-University Cooperative Research Center of the National Science Foundation (NSF), through membership fees under the direction of the Industry Advisory Board provided through NSF award no. 1266057 and no. 1841112 . We thank the NOAA Northeast Fisheries Science Center for making the data sets used in this study available, and we acknowledge the scientists and crew who participated in the depletion experiments at sea.

\section{Literature cited}

Chai, A.-L., M. Homer, C.-F. Tsai, and P. Goulletquer.

1992. Evaluation of oyster sampling efficiency of patent tongs and an oyster dredge. North Am. J. Fish. Manage. 12:825-832. Crossref

Clausen, S. E.

1998. Applied correspondence analysis: an introduction, $80 \mathrm{p}$. Sage Publ. Inc., Thousand Oaks, CA.

Da Ros, L., N. Nesto, C. Nasci, V. Moschino, D. Pampanin, and M. G. Marin.

2003. Biochemical and behavioural effects of hydraulic dredging on the target species Chamelea gallina. Fish. Res. 64:71-78. Crossref

Gedamke, T., W. D. DuPaul, and J. M. Hoenig.

2005. Index-removal estimates of dredge efficiency for sea scallops on Georges Bank. North Am. J. Fish. Manage. 25:1122-1129. Crossref

Gilkinson, K. D., G. B. J. Fader, D. C. Gordon, R. Charron, D. McKeown, D. Roddick, and Q. Liu.

2003. Immediate and longer-term impacts of hydraulic clam dredging on an offshore sandy seabed: effects on physical habitat and processes of recovery. Cont. Shelf Res. 23:1315-1336. Crossref

Gilkinson, K. D., D. C. Gordon, K. G. MacIsaac, D. L McKEown,

E. L. R. Kenchington, C. Bourbonnais, and W. P. Vass.

2005. Immediate impacts and recovery trajectories of macrofaunal communities following hydraulic clam dredging on Banquereau, eastern Canada. ICES J. Mar. Sci. 62:925-947. Crossref 
Hauton, C., T. R. W. Howell, R. J. A Atkinson, and P. G. Moore. 2007. Measures of hydraulic dredge efficiency and razor clam production, two aspects governing sustainability within the Scottish commercial fishery. J. Mar. Biol. Assoc. U.K. 87:869-877. Crossref

Hennen, D. R., L. D. Jacobson, and J. Tang.

2012. Accuracy of the Patch model used to estimate density and capture efficiency in depletion experiments for sessile invertebrates and fish. ICES J. Mar. Sci. 69:240-249. Crossref

Lambert, J., and P. Goudreau.

1996. Performance of the New England hydraulic dredge for the harvest of Stimson's surf clams (Mactomeris polynyma). Can. Ind. Rep. Fish. Aquat. Sci. 235, 28 p. [Available from website.]

Lasta, M. L., and O. O. Iribarne.

1997. Southwestern Atlantic scallop (Zygochlamys patagonica) fishery: assessment of gear efficiency through a depletion experiment. J. Shellfish Res. 16:59-62.

Leslie, P. H., and D. H. S. Davis. 1939. An attempt to determine the absolute number of rats on a given area. J. Anim. Ecol. 8:94-113.

Meseck, S. L., R. Mercaldo-Allen, J. M. Rose, P. Clark, C. Kuropat,

J. J. Pereira, and R. Goldberg.

2014. Effects of hydraulic dredging for Mercenaria mercenaria, northern quahog, on sediment biogeochemistry. J. World Aquat. Soc. 45:301-311. Crossref

Meyer, T. L., R. A. Cooper, and K. J. Pecci.

1981. The performance and environmental effects of a hydraulic clam dredge. Mar. Fish. Rev. 43(9):14-22.

Morson, J. M., D. M. Munroe, K. A. Ashton-Alcox, E. N. Powell,

D. Bushek, and J. Gius.

2018. Density-dependent capture efficiency of a survey dredge and its influence on the stock assessment of eastern oysters (Crassostrea virginica) in Delaware Bay. Fish. Res. 205:115-121. Crossref

Moschino, V., M. Deppieri, and M. G. Marin.

2003. Evaluation of shell damage to the clam Chamelea gallina captured by hydraulic dredging in the Northern Adriatic Sea. ICES J. Mar. Sci. 60:393-401. Crossref

NEFSC (Northeast Fisheries Science Center).

2010a. Monkfish (goosefish) stock assessment for 2010. In 50th Northeast regional stock assessment workshop (50th SAW) assessment report, p. 15-392. Northeast Fish. Sci. Cent. Ref. Doc. 10-17. [Available from website.]

2010b. Atlantic sea scallop stock assessment for 2010. In 50th Northeast regional stock assessment workshop (50th SAW) assessment report, p. 393-708. Northeast Fish. Sci. Cent. Ref. Doc. 10-17. [Available from website.]

2017a. 61st Northeast regional stock assessment workshop (61st SAW) assessment report. Northeast Fish. Sci. Cent. Ref. Doc. 17-05, 466 p. [Available from website.]

2017b. 63rd Northeast regional stock assessment workshop (63rd SAW) assessment report. Northeast Fish. Sci. Cent. Ref. Doc. 17-10, 409 p. [Available from website.]
NMFS (National Marine Fisheries Service).

2011. Fisheries economics of the United States, 2009. NOAA Tech. Memo. NMFS-F/SPO-118, 172 p.

Paloheimo, J. E., and L. M. Dickie. 1964. Abundance and fishing success. Rapp. P.-v. Réun. Cons. Int. Exp. Mer 155:152-163.

Parker, P. S.

1971. History and development of surf clam harvesting gear. NOAA Tech. Rep. NMFS CIRC-364, $15 \mathrm{p}$.

Pezzuto, P. R., C. Schio, and T. C. M. Almeida.

2010. Efficiency and selectivity of the Anomalocardia brasiliana (Mollusca: Veneridae) hand dredge used in southern Brazil. J. Mar. Biol. Assoc. U.K. 90:1455-1464. Crossref

Poussard, L. M., E. N. Powell, and D. R. Hennen.

2021. Efficiency estimates from depletion experiments for sedentary invertebrates: evaluation of sources of uncertainty in experimental design. Fish. Res. 234:10586. Crossref

Powell, E. N., K. A. Ashton-Alcox, and J. N. Kraeuter.

2007. Reevaluation of eastern oyster dredge efficiency in survey mode: application in stock assessment. North Am. J. Fish. Manage. 27:492-511. Crossref

$\mathrm{R}$ Core Team.

2019. R: a language and environment for statistical computing. R Foundation for Statistical Computing, Vienna, Austria. [Available from website, accessed April 2019.]

Ragnarsson, S. A., and G. G. Thórarinsdóttir.

2002. Abundance of ocean quahog, Arctica islandica, assessed by underwater photography and a hydraulic dredge. J. Shellfish Res. 21:673-676.

Rago, P. J., J. R. Weinberg, and C. Weidman.

2006. A spatial model to estimate gear efficiency and animal density from depletion experiments. Can. J. Fish. Aquat. Sci. 63: 2377-2388. Crossref

Sala, A., J. Brčić, B. Herrmann, A. Lucchetti, and M. Virgili. 2017. Assessment of size selectivity in hydraulic clam dredge fisheries. Can. J. Fish. Aquat. Sci. 74:339-348. Crossref

Skalski, J. R., D. S. Robson, and C. L. Matsuzaki.

1983. Competing probabilistic models for catch-effort relationships in wildlife censuses. Ecol. Model. 19:299-307. Crossref

Sokal, R. R., and F. J. Rohlf.

1998. Biometry: the principals and practice of statistics in biological sciences, 3rd ed., 887 p. W. H. Freeman and Co., New York.

Vølstad, J., G. Davis, A. Sharov, and B. Davis.

2000. A method for estimating dredge catching efficiency for blue crabs, Callinectes sapidus, in Chesapeake Bay. Fish. Bull. 98:410-420.

Wilberg, M. J., J. M. Robinson, S. A. M. Rains, J. L. Humphrey, and R. N. Lipcius.

2013. Effects of location errors on estimates of dredge catchability from depletion based methods. Fish. Res. 148:1-8. Crossref 